U.S. DEPARTMENT OF THE INTERIOR

U.S. GEOLOGICAL SURVEY

\title{
An empirical equation for modeling rare earth element mineral-mineral partitioning: An application to mantle metasomatism
}

by

James R. Budahn ${ }^{1}$

Open-File Report 91-596

This report is preliminary and has not been reviewed for conformity with U.S. Geological Survey editorial standards (or with the North American Stratigraphic Code). Any use of trade, product or firm names is for descriptive purposes only and does not imply endorsement by the U.S. Government.

${ }^{1}$ U.S. Geological Survey, DFC, Box 25046, MS 974, Denver, CO 80225 1995 


\section{ABSTRACT}

An empirical equation that is a function of mineral-melt partition coefficients is used to explain how the rare earth elements (REE) partition into minerals during closed-system crystallization of coarsely-crystalline rock. The concentration of any REE in a mineral as described by this equation is shown to depend on two factors: (1) the affinity of the mineral to incorporate the REE relative to the affinities of all the other minerals in the rock to incorporate that REE and (2) the modal abundance of the mineral in the rock. The general form of the equation for any $R E E$ is ( $D^{\mathrm{MIN}} /$ sumD) $C^{\mathrm{WR}} / \mathrm{x}_{\mathrm{MIN}}=C^{\mathrm{MIN}}$, where $D^{\mathrm{MIN}}$ is the mineral-melt REE partition coefficient for a constituent mineral; sumD is the sum of the $D^{M I N}$ values for all the minerals in the rock; $C^{W R}$ is the concentration of a REE in the whole-rock; $x_{M I N}$ is the weight fraction of the mineral in the rock; and $\mathrm{c}^{\mathrm{MN}}$ is the concentration of a REE in the mineral. Calculations using this equation and the REE compositions of constituent minerals indicate the proportions of mineral phases in the host rock. These calculations also constrain the values of partition coefficients that must be operative under the conditions of crystallization. The concept of mineral-mineral partitioning represented by this equation accounts for the REE enrichment and the distinctive REE patterns observed in different portions of a metasomatized peridotite-hornblendite xenolith from Dish Hill, CA. A magmatic liquid, now represented by the amphibole-bearing (hornblendite) vein, provided the REE that partitioned into the coexisting peridotite. The present REE patterns are in accordance with the contrasting partition coefficients of the amphibole and the original peridotite and are in response to the time-temperaturepressure conditions of partitioning. Within $1 \mathrm{~cm}$ of the vein, the operative partition coefficients for amphibole and peridotite approximate equilibrium values, indicating that equilibrium conditions were attained in this portion of the xenolith. At increasing distance $(2-5 \mathrm{~cm})$ from the vein, operative partition coefficients do not correspond to equilibrium values, suggesting that magma-peridotite interactions were incomplete.

A third potential application of this equation may include explaining REE redistribution in metamorphic recrystallization. 


\section{INTRODUCTION}

Mineral-melt partition coefficients of trace elements, especially the rare earth elements (REE), are widely employed to model igneous processes such as partial melting and crystal fractionation (McKay, 1989). Equations that quantify these processes (Neumann et al., 1954; Schilling, 1966; Gast, 1968; Shaw, 1970) are functions of these coefficients and explain how silicate melt compositions are affected by the interaction of the magma with mineral phases. The partition coefficient ( $D^{\mathrm{MIN}}$ ) is defined as the concentration of an element in a mineral ( $\mathrm{C}^{\mathrm{MN}}$ ) relative to its concentration in a coexisting liquid $\left(C^{L}\right)$ or whole-rock ( ${ }^{\mathrm{WR}}$ ), the latter represented by either a quenched glass or fine-grained matrix. Most REE partition coefficients are determined by measuring the trace element concentration in a small ( $<10 \%)$ fraction of mineral crystals and in the surrounding matrix (McKay, 1989). Published partition coefficients indicate a consistent tendency for certain minerals to selectively incorporate certain REE from coexisting melts (Irving, 1978; Irving and Frey, 1984). Therefore, variations in the shapes of REE patterns in magmatic liquids can indicate the mineral phases with which the liquid last equilibrated (Hanson, 1989).

There are no studies that quantify REE partitioning among the constituent minerals of coarse-grained rocks. Examples of these are ultramafic rocks that contain olivine (ol), orthopyroxene $(o p x)$, clinopyroxene (cpx), spinel (spn) and garnet (gar). It is apparent from comparing REE concentrations in individual minerals to those in the host whole-rocks (Reid and Frey, 1971; Kurat et al., 1980; Bodinier et al., 1987; and Song and Frey, 1989) that D values cannot be calculated by the relationship $\mathrm{D}^{\mathrm{MIN}}=\mathrm{C}^{\mathrm{MIN}} / \mathrm{C}^{\mathrm{WR}}$ (McKay, 1989). For example, in ultramafic rocks that contain garnet, the coexisting $\mathrm{cpx}$ is very depleted in the HREE (e.g., Philpotts et al., 1972; Bodinier et al., 1987), but no such depletion is observed in cpx that is experimentally equilibrated with silicate melts. Because REE abundance ratios for some coexisting mineral pairs produce consistent patterns (e.g., Philpotts et al., 1972; Stosch, 1982), it is commonly accepted that REE concentrations in coexisting minerals are directly related to their partition coefficients. However, plots of REE abundance ratios exhibit a considerable range (as much as a factor of three) that is unexpected for rocks that are compositionally similar and that most likely crystallized under similar temperatures and pressures. This observation suggests that REE partition coefficient ratios (i.e., $D^{\mathrm{MIN}} / \mathrm{D}^{\mathrm{MIN}}$ ) are not equivalent to their corresponding abundance ratios $\left(\mathrm{C}^{\mathrm{MIN} 1} / \mathrm{C}^{\mathrm{MIN} 2}\right)$.

Equilibrium partition coefficients of the REE are functions of temperature, pressure, and mineral and melt compositions (see McKay, 1989), but these partition coefficients are independent of the types of co-crystallizing mineral phases. Thus, when modeling crystal fractionation processes involving a multi-phase mineral 
assemblage, the bulk D value for the rock is defined as the sum of $x_{M I N} D^{M I N}$, where $x_{\text {MIN }}$ is the weight fraction of each mineral phase and $D^{M}$ is the individual mineral-melt partition coefficient. The individual $D$ values are not adjusted based on the types of coexisting mineral phases in the assemblage; therefore, variations in $D$ values related to the presence or absence of certain minerals cannot be used to explain the REE abundance patterns for the minerals in multi-phase rocks.

This paper presents an empirical equation that successfully accounts for the observed REE compositions of minerals in ultramafic rocks. The equation describes the REE concentrations in a specific mineral to be dependent on all the constituent minerals in the rock (i.e., on all the mineral-melt partition coefficients) and on the modal abundance of the mineral in the rock. In previous calculations of this type, only pairs of mineral-melt partition coefficients were considered in estimating the REE concentrations in a coexisting mineral; the influence of other minerals in the rock were ignored. Calculations using the proposed equation are applicable to any rock that has crystallized under closed system conditions, which are defined as (1) primary crystallization of mineral phases from a volume of liquid or (2) recrystallization of minerals in a closed system composed of rock and an introduced liquid (metasomatism). A primary reason for deriving this equation was to examine the role of mineral-mineral partitioning during metasomatic alteration, and all discussion is oriented towards this application. Although other models of mantle metasomatism based on REE abundances have been proposed (Prinzhofer and Allegre, 1985; Navon and Stolper, 1987; Bodinier et al., 1990; Liang and Elthon; 1990), these models (1) are generally limited to considering mantle rocks with very low initial REE concentrations and/or low bulk D values (e.g., dunites and harzburgites); (2) are highly dependent on the location in the mantle of the individual xenolith relative to an ascending magma, which develops a wide-ranging REE pattern; or (3) predict REE variations in wallrocks as a function of distance from the vein that are not observed in the Dish Hill xenolith. The mineral-mineral partitioning equation was derived to provide a more general solution that quantitatively accounts for the variations in both REE abundances and patterns under a wide variety of mantle metasomatic conditions.

\section{GARNET PYROXENITE REE DATA}

Examination of REE abundance patterns in minerals of ultramafic rocks and of other rock types, such as metamorphic granulites (e.g., Grauch, 1989), suggests that an important process in producing these patterns is some form of mineral-mineral interaction. As stated above, ultramafic rocks that contain garnet show unusually depleted HREE abundance patterns in coexisting clinopyroxenes. The questions arise: (1) can experimentally derived mineral-melt partition coefficients account for the observed REE abundance variations in the constituent minerals; and 
(2) Are there other mineralogical factors that affect the REE concentrations in the minerals?

The sample selected for this examination is a garnet pyroxenite from salt Lake Crater, Hawaii, that contains mineral phases with contrasting mineral-melt partition coefficients. High-quality REE data for the whole-rock, garnet and clinopyroxene (Reid and Frey, 1971) are reproduced in Table 1. The reported modal composition is $65 \% \mathrm{cpx}, 18 \%$ gar and $17 \%$ ol+ component (ol, opx and spinel). The chondrite-normalized REE patterns for the whole-rock, cpx and gar are depicted in Fig. 1. No REE data are available for the ol+ component.

\section{REE MINERAL-MINERAL PARTITIONING EQUATION}

The fundamental requirement for deriving the equation to calculate REE concentrations in a mineral ( ${ }^{M I N}$ ) was that it take into account the affinity of all the constituent minerals in the rock to incorporate the REE. The affinity of a mineral to incorporate a REE is assumed to be proportional to its partition coefficient. The mineral-mineral partitioning equation to calculate $C^{\mathrm{MIN}}$ must also satisfy the mass balance requirement that $x_{M I N} C^{M I N}+x_{b} C^{b}+x_{c} C^{c}+\ldots=c^{W R}$, where $x_{M I N}, x_{b}, x_{c}$, etc., are the weight fractions of mineral phases MIN, $b, c$, etc., in the rock; $C^{M I N}$, $C^{b}, C^{c}$, etc., are the concentrations of any REE in the minerals; and $C^{\mathrm{WR}}$ is the concentration of any REE in the wholerock.

The equation that was ultimately derived describes the relative concentration of a given $R E E$ in a mineral phase as a function of the ratio $D^{M I N} /$ sumD, where $D^{\text {MIN }}$ is the mineral-melt partition coefficient for that phase and sumb is the sum of the partition coefficients for all the mineral phases in the rock. The $\mathrm{D}^{\mathrm{MIN}}$ /sumD ratio is comparable to a weighting factor that expresses the relative influence of a given mineral on the overall partitioning of a REE in a closed system. From mass balance requirements, the equation defines the absolute REE concentrations in a mineral phase to be inversely proportional to the weight fraction of the mineral $\left(x_{\mathrm{MIN}}\right)$ in the rock.

The general form of this equation is:

$$
\left[D^{\mathrm{MIN}} /\left(D^{\mathrm{MIN}}+D^{\mathrm{b}}+\mathrm{D}^{\mathrm{c}}+\ldots\right)\right] \mathrm{C}^{\mathrm{WR}} / \mathrm{x}_{\mathrm{MIN}}=\mathrm{C}^{\mathrm{MIN}},
$$

where $D^{M I N}, D^{b}, D^{c} \ldots$ etc., are the respective mineral-melt partition coefficients of a REE for phases MIN, b, c, etc.

The garnet pyroxenite data were used to test the validity of Eqn. 1. Whole-rock concentrations $\left(C^{\mathrm{WR}}\right)$ and the mineral data for $\mathrm{cpx}\left(\mathrm{x}_{\mathrm{cpx}}=0.65\right.$ and $\left.\mathrm{C}^{\mathrm{cpx}}\right)$ are incorporated in Eqn. 1 to calculate for each of the REE, the ratios $D^{\text {cpx }} /$ sumD, where sumD $=D^{c p x}+D^{\text {gar }}+D^{\text {ol }}+D^{\text {opx }}+D^{\text {spn }}$. On the basis of these calculated ratios and the published D values for cpx of Irving and Frey (1984), the apparent D values for garnet 


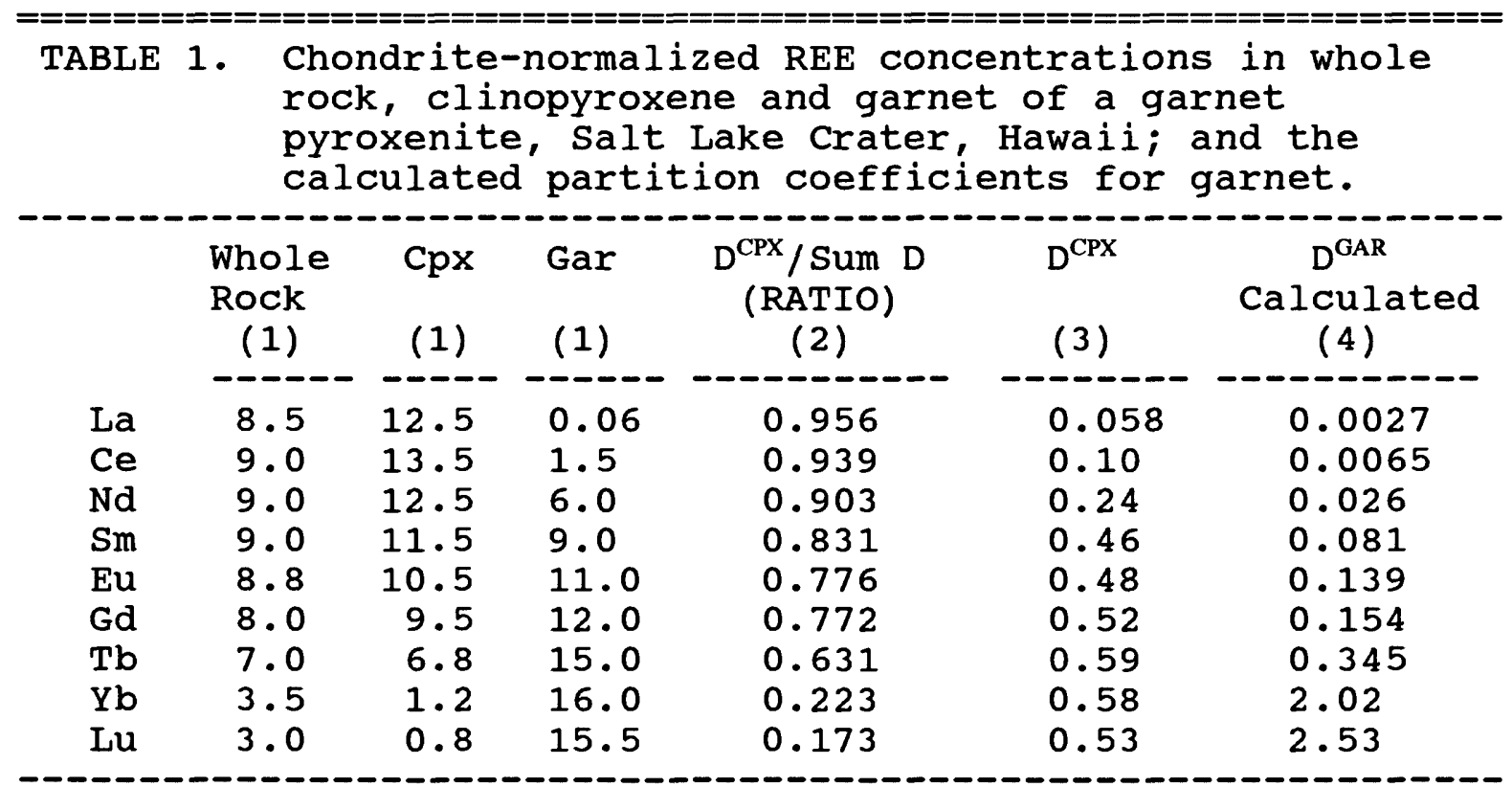

1. Concentration are interpolated data of Reid and Frey, 1971; actual REE data are plotted in Figure 1.

2. $\mathrm{D}^{\mathrm{CPX}} /$ Sum $\mathrm{D}=\mathrm{RATIO}=0.65 * \mathrm{C}^{\mathrm{CPX}} / \mathrm{C}^{\mathrm{WR}}$ using the $\mathrm{cpx}\left(\mathrm{C}^{\mathrm{CPX}}\right)$ and whole rock ( $C^{W R}$ ) concentrations from this table.

3. Irving and Frey, 1984.

4. $D^{\text {GAR }}=\left(D^{\text {CPX }}-\right.$ RATIO* $\left.D^{\text {CPX }}\right) /$ RATIO

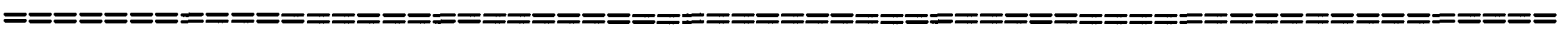

are determined. In this exercise, it was only of interest to determine if $D^{\mathrm{cpx}} /$ sumD ratios and the relative REE concentrations in $\mathrm{cpx}$ are correlated with $\mathrm{D}^{\mathrm{gar}}$ values; therefore, the partition coefficients for ol, opx and spinel were set equal to 0 . The calculation of $\mathrm{D}^{\mathrm{gar}}$ from $\mathrm{D}^{\mathrm{cpx}}$ was made because the published $\mathrm{D}$ values for cpx are less variable than those for garnet and the REE abundance pattern in $\mathrm{cpx}$ is better constrained by the analytical data.

Results of the calculations are presented in Table 1 and Fig. 2. As depicted in Fig. 2, the calculated values of $D^{\text {gar }}$ for the REE are consistent with published experimental values of $D^{\text {gar }}$ under mantle conditions (Shimizu and Kushiro, 1975; Irving and Frey, 1978). This agreement suggests that the garnet pyroxenite crystallized at or near equilibrium conditions. The larger discrepancy in the $\mathrm{D}^{\mathrm{gar}}$ values for $\mathrm{La}$ is explained by the omission of the ol, opx and spinel phases that have $D$ values for La that are comparable to the $\mathrm{D}^{\mathrm{gar}}$ values.

Probably the most important feature of Eqn. 1 is its ability to predict the relative proportions of minerals in a rock and the required partition coefficients, provided that the REE compositions of the minerals are known. As indicated from simple mass balance, 
the concentration of any REE in the garnet pyroxenite whole-rock $\left(C^{W R}\right)$ is given by:

$$
\mathrm{x}_{\mathrm{cpx}} \mathrm{C}^{\mathrm{cpx}}+\mathrm{x}_{\mathrm{gar}} \mathrm{C}^{\mathrm{gar}}+\mathrm{x}_{\mathrm{ol}+} \mathrm{C}^{\mathrm{ol}+}=\mathrm{C}^{\mathrm{WR}}
$$

In this equation, $x_{c p x}, x_{g a r}$ and $x_{0 l+}$ represent the weight fractions, and $C^{c p x}, C^{g a r}$ and $C^{\text {olt }}$ are the REE concentrations, of cpx, gar and the composite ol+opx+spinel phase, respectively. Because the composition of the olt phase is not available, the REE concentrations in this component will be estimated from other published mineral data for use in subsequent calculations. By substituting this expression for $C^{\mathrm{WR}}$ into the form of Eqn. 1 that expresses $C^{c p x}$ concentrations, the following equation is obtained:

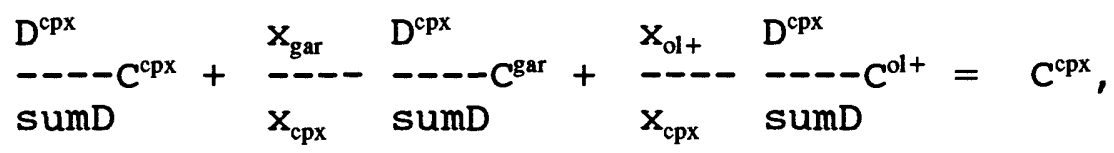

where sumD $=D^{\text {cpx }}+D^{\text {gar }}+D^{\text {ol }+}$. A set of these equations, one for each measured $R E E$, is used to calculate the relative weight fractions $\mathrm{x}_{\mathrm{gar}} / \mathrm{x}_{\mathrm{cpx}}$ and $\mathrm{x}_{\mathrm{ol}+} / \mathrm{x}_{\mathrm{cpx}}$ in the whole-rock. The solution does not require that the whole-rock concentrations be known. The calculation of $\mathrm{C}^{\mathrm{cpx}}$ concentrations is made because most of the REE are contained in cpx.

The method for determining values of $x_{\mathrm{gar}} / \mathrm{x}_{\mathrm{cpx}}$ and $\mathrm{x}_{\mathrm{ol}} / \mathrm{x}_{\mathrm{cpx}}$ is as follows: The $D^{c p x} /$ sumD ratios are first estimated for each $\mathrm{REE}$ using published partition coefficients. The values for $D^{\text {gar }}$ calculated in the preceding evaluation are ignored. These ratios are multiplied by the respective measured REE concentrations for $c p x$ ( ${ }^{c p x}$ ), gar $\left(\mathrm{C}^{\mathrm{gar}}\right)$ and ol+ $\left(\mathrm{C}^{\mathrm{ol}+}\right)$. The values of $\mathrm{x}_{\mathrm{gar}} / \mathrm{x}_{\mathrm{cpx}}$ and $\mathrm{x}_{\mathrm{ol}+} / \mathrm{x}_{\mathrm{cpx}}$ that satisfy the matrix of these equations for each selected REE are determined by multi-linear least-squares regression analysis (MLRA) methods. It is assumed that the REE partition coefficients for cpx relative to the sum of all the minerals are known exactly, and, therefore, the coefficient of the first terms in Eqn. 3, designated as TOT in Table $2 \mathrm{~A}$, is set equal to 1.0 .

The input parameters and the results of the preliminary calculations are presented in Table 2A. Although these calculations were complicated by the lack of REE data for the olt phase, a reasonable estimate of this composite phase was obtained from published mineral data for ol, opx and spinel (Frey, 1970). There is, however, very poor constraint on the $x_{o l} / x_{c p x}$ ratio, as indicated by the large uncertainty of this value (Table 2A). 


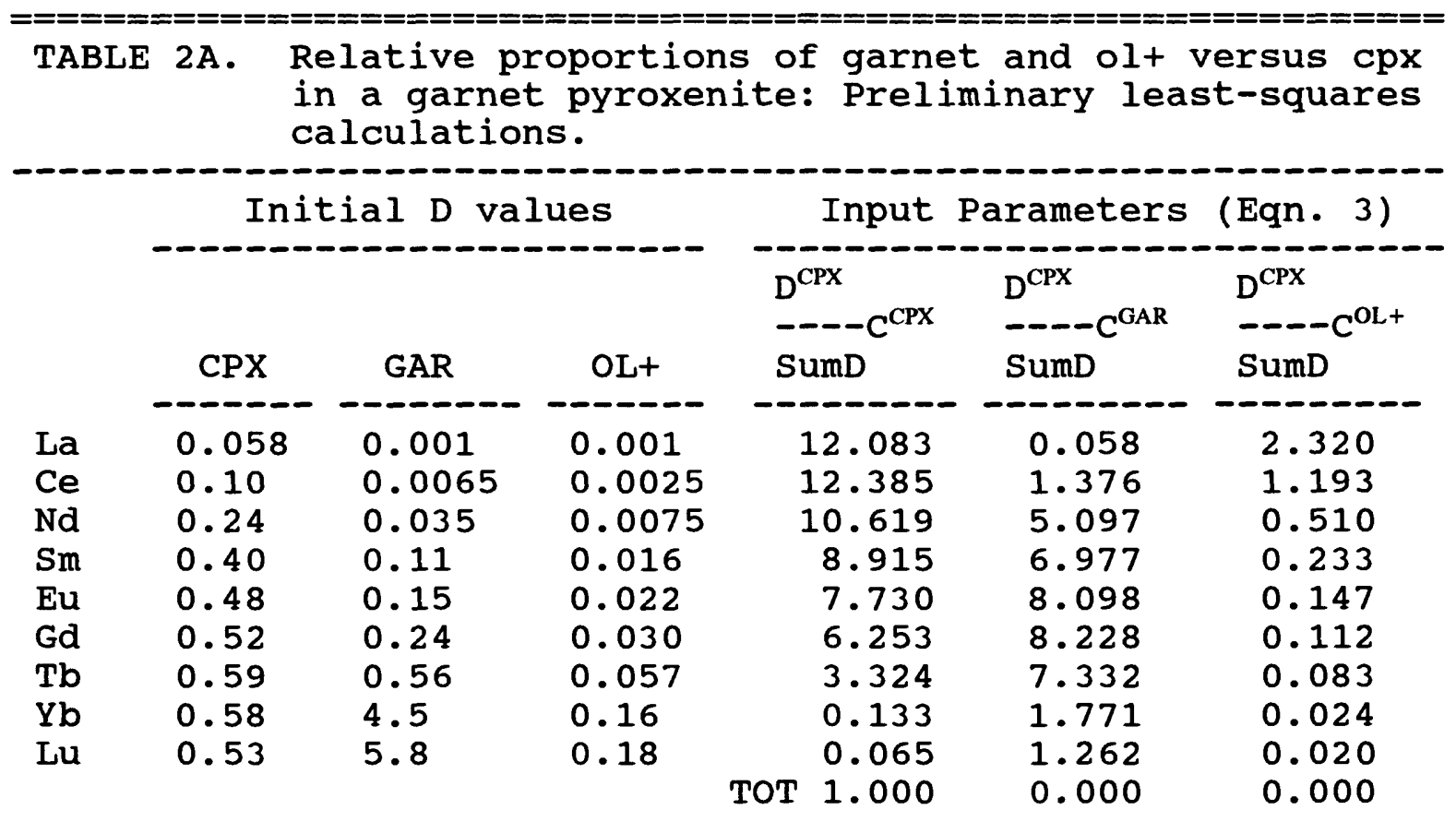

Results

\begin{tabular}{|c|c|c|c|c|c|c|}
\hline \multirow[t]{14}{*}{$x_{\mathrm{gar}} / \mathrm{x}_{\mathrm{cpx}}$} & \multirow[t]{4}{*}{$=0$} & $473+-0$ & 38 & $+/ x_{\mathrm{cpx}}=$ & 0.349 & $t-0.389$ \\
\hline & & & $\mathrm{PX}$ & & Pct & Pct \\
\hline & & Observed & Calc & Diff & Diff & Sig \\
\hline & & $\cdots-\cdots$ & ------ & ----- & $-\cdots$ & $-\cdots-\cdots$ \\
\hline & La & 12.50 & 12.56 & 0.06 & 0.5 & 10.0 \\
\hline & $\mathrm{Ce}$ & 13.50 & 13.08 & -0.42 & -3.2 & 10.0 \\
\hline & $\mathrm{Nd}$ & 12.50 & 12.89 & 0.39 & 3.1 & 10.0 \\
\hline & $\mathrm{Sm}$ & 11.50 & 12.03 & 0.53 & 4.6 & 10.0 \\
\hline & $\mathrm{Eu}$ & 10.50 & 11.38 & 0.88 & 8.4 & 10.0 \\
\hline & Gd & 9.50 & 10.00 & 0.50 & 5.2 & 10.0 \\
\hline & $\mathrm{Tb}$ & 6.80 & 6.72 & -0.08 & -1.2 & 10.0 \\
\hline & $\mathrm{Yb}$ & 1.20 & 0.98 & -0.22 & -23.1 & 20.0 \\
\hline & $\mathrm{Lu}$ & 0.80 & 0.67 & -0.13 & -20.0 & 20.0 \\
\hline & TOT & 1.00 & 0.97 & -0.03 & -3.1 & 5.0 \\
\hline
\end{tabular}




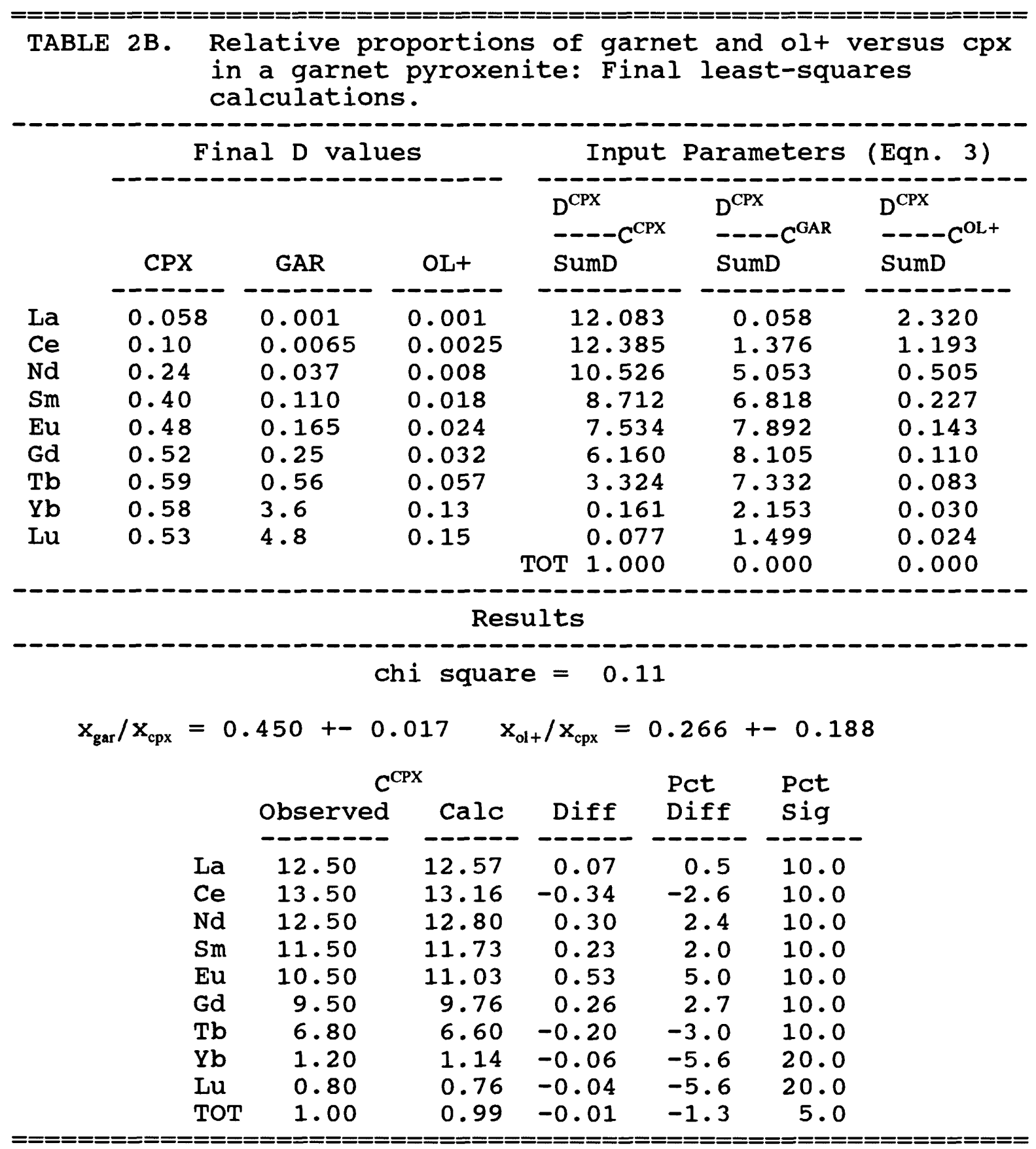


The differences between the calculated (Eqn. 3) and observed $C^{c p x}$ concentrations are attributed to the selection of inappropriate $D$ values for the REE at the conditions under which the garnet pyroxenite crystallized. On the basis of these differences, the $\mathrm{D}^{\text {gar }}$ and $D^{\text {olt }}$ values are adjusted to produce a better fit to the observed cpx composition. Values of $D^{\mathrm{cpx}}$ are not adjusted because these values are considered to be relatively invariant. The partition coefficients for gar and olt are raised about $10 \%$ for the middle REE and lowered by $\sim 20 \%$ for $\mathrm{Yb}$ and $\mathrm{Lu}$. Least-squares calculations were repeated using these adjusted values (Table 2B). The ratios of $x_{\mathrm{gar}} / \mathrm{x}_{\mathrm{cpx}}$ and $\mathrm{x}_{\mathrm{ol}+} / \mathrm{x}_{\mathrm{cpx}}$ changed only slightly from 0.47 to 0.45 and from 0.35 to 0.27 , respectively. The weight fraction of $\mathrm{cpx}$ is estimated to be 0.58 (or 58\%) from the relationship $1+\mathrm{x}_{\mathrm{gar}} / \mathrm{x}_{\mathrm{cpx}}+$ $x_{\mathrm{ol}+} / \mathrm{x}_{\mathrm{cpx}}=1 / \mathrm{x}_{\mathrm{cpx}}$ and using calculated values of $\mathrm{x}_{\mathrm{gar}} / \mathrm{x}_{\mathrm{cpx}}=0.45$ and $x_{\mathrm{ol}+} / \mathrm{x}_{\mathrm{cpx}}=0.27$. For $\mathrm{x}_{\mathrm{cpx}}=0.58$, the estimated weight fraction of garnet is $0.26(26 \%)$ and of the olt phase is $0.16(16 \%)$. These estimates compare favorably to the reported modal abundances of $65 \% \mathrm{cpx}, 18 \%$ gar and 17\% ol+opx+spinel and indicate that the relative proportions of mineral components in a rock can be derived using the REE concentrations in the minerals and reasonable estimates of the D values for the mineral phases. This type of calculation also provides a basis for determining the most appropriate mineral-melt partition coefficients for the conditions of crystallization.

\section{THE PARTITIONING MODEL FOR A HYPOTHETICAL AMPHIBOLE: GARNET PYROXENITE}

In order to better understand how the mineral-mineral partitioning equation was applied to the process of mantle metasomatism, a form of Eqn. 1 was applied to a hypothetical rock "system" composed of the same garnet pyroxenite mineral assemblage described above, plus an enclosing metasomatic liquid with a bulk composition equivalent to a mafic amphibole. The concentrations of all the REE in the liquid $\left(\mathrm{C}^{\mathrm{L}}\right)$ are taken to be $100 \mathrm{x}$ chondrite. The garnet pyroxenite is assumed to be impermeable to the liquid so that magma infiltration does not affect the final garnet pyroxenite composition. The time-temperature-pressure conditions for solid/melt interaction were sufficient, however, to allow for complete equilibration of the REE between the solid pyroxenite and liquid prior to the crystallization of the liquid to amphibole. The transport mechanism of REE partitioning, therefore, is solely diffusion. The equation suggested to account for the REE concentrations in the metasomatically altered garnet pyroxenite is, by analogy to Eqn. 1:

$$
\left[D^{\mathrm{GP}} /\left(D^{\mathrm{GP}}+D^{\mathrm{AMP}}\right)\right] \mathrm{C}^{\mathrm{SYS}} / \mathrm{x}_{\mathrm{GP}}=\mathrm{C}^{\mathrm{GP}-\mathrm{ALT}},
$$

where $D^{G P}$ is the bulk partition coefficient of any REE for the garnet pyroxenite ( $\left.D^{\mathrm{GP}}=0.65 \mathrm{D}^{\mathrm{cpx}}+0.18 \mathrm{D}^{\mathrm{gar}}+0.17 \mathrm{D}^{\mathrm{ol}+}\right) ; \mathrm{D}^{\mathrm{AMP}}$ is the partition coefficient of any REE for the amphibole; $\mathrm{C}^{\mathrm{SY}}$ is the 
concentration of any REE in the system composed of garnet pyroxenite plus liquid; $x_{G P}$ is the weight fraction of garnet pyroxenite; and $C^{\text {GP-ALT }}$ is the concentration of any REE in the altered garnet pyroxenite.

In the following application of this equation, it is assumed that there are equal weight fractions of the liquid and garnet pyroxenite in the system; i.e. $x_{L}=x_{G P}=0.5$. A REE concentration in this system ( $C^{S Y S}$ ) is therefore equal to $0.5 C^{L}+0.5 C^{G P}$. Because equilibrium conditions are assumed (i.e., the REE in both the garnet pyroxenite and the liquid are available to exchange and reequilibrate), the REE of the garnet pyroxenite are included in the system. During crystallization of the liquid to amphibole, the $C^{\text {sys }}$ concentrations are distributed into the solid amphibole ( ${ }^{A M P}$ ) and the altered garnet pyroxenite (C ${ }^{\text {GP-ALT}}$ ) in response to the partitioning effect between these two solid phases under the conditions of closed system crystallization. Thus, at the completion of crystallization, the $c^{\text {sYs }}$ concentrations are also given by $0.5 C^{\text {AMP }}+0.5 C^{\text {GP-ALT}}$, assuming that $R E E$ exchange does not appreciably affect the weights of the phases.

In Eqn. 4, the mineral phases in the garnet pyroxenite are not considered independently, but rather the garnet pyroxenite is treated as a single phase with a bulk $D$ value ( ${ }^{\mathrm{GP}}$ ) that is calculated in the same manner as a multi-phase mineral assemblage. Because the host garnet pyroxenite is assumed to be impermeable to the liquid, it is reasonable to conclude that individual mineral grains (e.g., cpx, gar, olt) did not directly partition the REE from the magma. The REE concentrations that are predicted for the crystallized amphibole ( $\mathrm{C}^{\mathrm{AMP}}$ ) and altered garnet pyroxenite (C ${ }^{\mathrm{GP}-\mathrm{ALT}}$ ) using Eqn. 4 are given in Table 3. The $C^{\text {SYs }}$ concentrations used in this example (Table 3 ) are calculated from the equation $\mathrm{x}_{\mathrm{L}} \mathrm{C}^{\mathrm{L}}+$ $x_{G P} C^{G P}$, using the $C^{L}$ and $C^{G P}$ concentrations of Table 3 and $x_{L}=0.5$ and $x_{G P}=0.5$. The $D^{A M P}$ and $D^{G P}$ values suggested to be operative under the conditions of crystallization are also given in Table 3 . The chondrite-normalized REE abundance patterns of the calculated amphibole and altered pyroxenite are depicted in Fig. 3 .

The results of this and similar calculations in which the weight fractions of liquid $\left(x_{L}\right)$ and garnet pyroxenite $\left(x_{G P}\right)$ were varied indicate that the REE concentrations in the original liquid $\left(C^{L}\right)$ can be expressed by the following empirical relationship:

$$
\mathrm{C}^{\mathrm{AMP}}+\mathrm{x}_{\mathrm{GP}} / \mathrm{x}_{\mathrm{AMP}}\left(\mathrm{C}^{\mathrm{GP}-\mathrm{ALT}}-\mathrm{C}^{\mathrm{GP}}\right)=\mathrm{C}^{\mathrm{L}} \text {. }
$$

A form of this equation is used below to estimate the composition of the original metasomatic liquid that interacted with a spinel lherzolite to produce the Dish Hill composite xenolith.

\section{COMPOSITE PERIDOTITE-HORNBLENDITE XENOLITH REE DATA}

A detailed description of the mineralogy and geochemistry of sample $\mathrm{BA}-2-1$, a metasomatized composite peridotite-hornblendite xenolith of Dish Hill, CA, is presented elsewhere (Wilshire et al., 


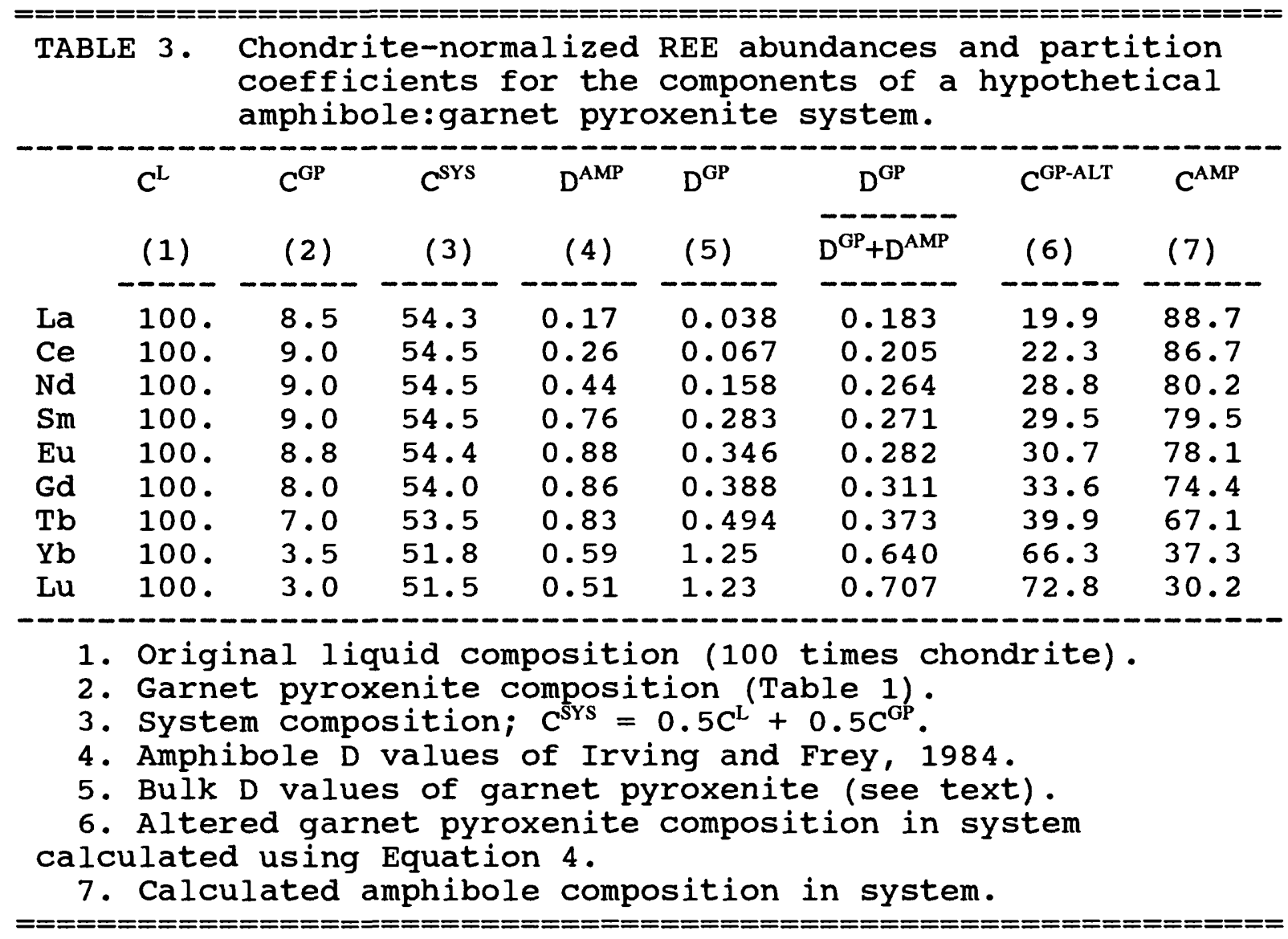

1980; Nielson and Noller, 1987; Nielson et al., 1993). This sample is a hydrous chrome-diopside-bearing spinel peridotite xenolith about $17 \mathrm{~cm}$ wide with a thin $(<7 \mathrm{~mm})$ hornblendite selvage at one end. This hornblendite is composed primarily of kaersutitic amphibole, but contains minor apatite and phlogopite. Major, minor and trace element abundances (including eight REE) were determined for five subsamples of the peridotite (Nielson et al., 1993), but only the REE data are presented here (Table 4, Fig. 4). These subsamples, designated WR-1 through WR-5, are about $1 \mathrm{~cm}$ wide and were taken at increasing distance (as much as about $8 \mathrm{~cm}$ ) from the amphibole selvage.

The more distant subsamples, WR-4 and WR-5, exhibit the most LREE-depleted patterns and are assumed to represent unaltered or unreacted peridotite. The subsamples closer to the selvage, WR-3 through WR-1, are progressively more REE-enriched relative to the unaltered samples. These three subsamples also contain pargasitic amphibole components of variable composition (Wilshire et al., 1988). Clinopyroxene separates from each subsample were analyzed for nine REE (Table 5 and Fig. 5). Although a sample of the amphibole-rich selvage was not available for analysis, the REE 


\begin{tabular}{|c|c|c|c|c|c|c|c|}
\hline \multirow[t]{3}{*}{$\mathrm{TAB}$} & E 4 & \multicolumn{6}{|c|}{$\begin{array}{l}\text { Rare earth element concentrations (in ppm) in whole } \\
\text { rock subsamples from the } \mathrm{BA}-2-1 \text { composite xenolith } \\
\text { and in two amphibole veins. }\end{array}$} \\
\hline & & & & & & \multicolumn{2}{|c|}{ AMP } \\
\hline & WR-1 & WR -2 & WR -3 & WR -4 & WR -5 & (1) & (2) \\
\hline La & 1.8 & 0.50 & 0.22 & 0.13 & 0.145 & 20.1 & 20.7 \\
\hline $\mathrm{Ce}$ & 5.4 & 1.25 & 0.70 & 0.53 & & 55.1 & 48.8 \\
\hline Nd & 3.4 & 0.90 & 0.55 & 0.55 & 0.58 & 40.0 & 32.4 \\
\hline $\mathrm{Sm}$ & 0.83 & 0.224 & 0.193 & 0.208 & 0.219 & 9.24 & 8.92 \\
\hline $\mathrm{Eu}$ & 0.315 & 0.095 & 0.082 & 0.093 & 0.095 & 3.34 & $(2.96)$ \\
\hline Gd & $(0.94)$ & $(0.38)$ & $(0.34)$ & $(0.35)$ & $(0.36)$ & 9.13 & 8.67 \\
\hline $\mathrm{Tb}$ & 0.145 & 0.071 & 0.066 & 0.063 & 0.065 & $(1.27)$ & $(1.22)$ \\
\hline Yb & 0.56 & 0.37 & 0.33 & 0.37 & 0.35 & 2.93 & 2.86 \\
\hline $\mathrm{Lu}$ & 0.083 & 0.057 & 0.053 & 0.058 & 0.055 & $(0.39)$ & $(0.35)$ \\
\hline
\end{tabular}

Values in parentheses are interpolated or extrapolated.

1. REE concentrations in the amphibole vein of BA-2-1 Dish

Hill composite xenolith (Menzies et al., 1985).

2. REE concentrations in the amphibole vein of $B A-1-72$ composite xenolith (Menzies et al., 1985).

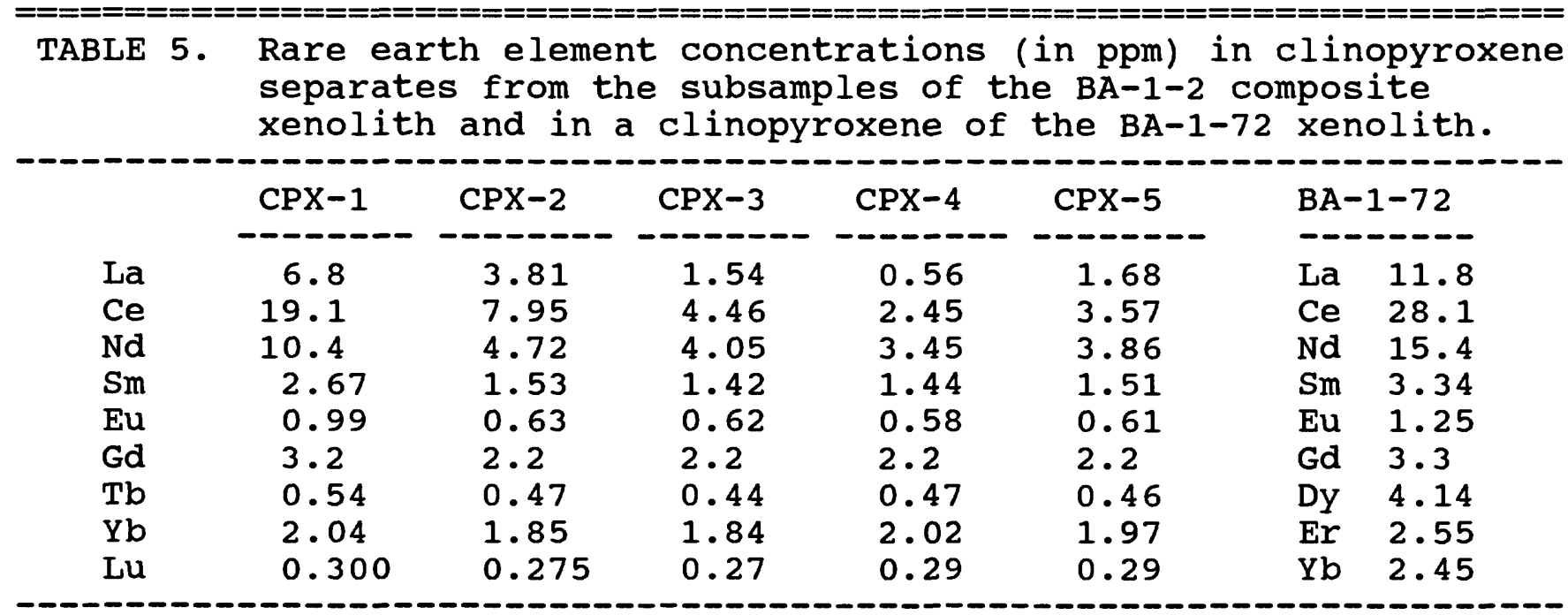

REE concentrations in cpx of BA-1-72 from Menzies et al., 1985. 
compositions of amphibole selvages from this and another composite xenolith from Dish $\mathrm{Hill}$ are reported by Menzies, et al. (1985). These two amphibole selvages are very similar in REE composition (Table 4), and an average composition (Fig. 4) is used in the model calculations. The concentration of $\mathrm{Tb}$ required for modeling was interpolated from the available chondrite-normalized REE abundance data; the concentration of Lu was extrapolated.

The REE data of this xenolith are used in combination with the empirical equation (Eqn. 1) to calculate the apparent partition coefficients of the amphibole and peridotite that were operative under the conditions of mantle metasomatism, and, therefore, to account for the observed REE variations in the peridotite. There are two basic assumptions for this model. (1) The hornblendite selvage crystallized from a metasomatic liquid that was brought into contact with the peridotite. This assumption is supported by the observation that kaersutite amphiboles commonly occur in dikes in massive peridotites (Wilshire, 1984; Wilshire et al., 1988). (2) The amphibole and the peridotite have not been altered by subsequent mantle processes. These assumptions imply that the REE of the original, introduced metasomatic liquid are now contained in the hornblendite selvage and in the REE-enriched peridotite subsamples, WR-1 through WR-3.

As shown in Fig. 6, calculations that assume simple mixing (Fig. 7A) of the amphibole vein material with unreacted peridotite (either WR-4 or WR-5) produce LREE-enriched abundance patterns that are grossly similar to those observed in the metasomatized WR-1 and WR-2 subsamples. However, these calculations fail to account for two distinctive features of the REE patterns: (1) the positive Eu anomaly (i.e., (Eu/Sm) ${ }_{N}$ is about 1.0) in the WR-1 subsample and (2) the U- or V-shaped REE pattern of WR-2 (Fig. 6). The positive Eu anomaly is analytically significant and is confirmed by similar Eu anomalies in the clinopyroxene of WR-1 and in a cpx phase contained in another Dish Hill xenolith (BA-1-72; Fig. 5) reported by Menzies et al. (1985). From these discrepant features, it is inferred that some type of mineral-mineral partitioning (Figs. 7B and 7C) during the metasomatic process has created the REE patterns in WR-1, WR-2 and WR-3 subsamples. Simple mixing is regarded to be limited to within a few millimeters of the peridotite-hornblendite contact in modifying the REE compositions of this xenolith.

\section{REE PARTITIONING MODELS FOR MANTLE METASOMATISM}

In contrast to the hypothetical amphibole-garnet pyroxenite system, the BA-2-1 composite xenolith cannot be treated as a simple two- component system. It is apparent from the variations in REE abundance patterns among the subsamples (Fig. 4) that the entire peridotite portion of the xenolith is not in equilibrium with the amphibole vein. Nevertheless, equilibrium conditions may have been attained or closely approached on the scale of individual subsamples. The approach of each subsample to an equilibrium condition can be estimated by modeling REE partitioning using a 
"subsystem" composed of a single peridotite subsample and the amphibole vein. The three subsystems that are modeled utilize subsamples WR-1, WR-2 and WR-3. Each calculation utilizes the REE composition of the given subsamples (Table 4), an averaged REE composition of the amphibole (see below) and a form of Eqn. 1 . The apparent partition coefficients for the peridotite subsample and amphibole that are required to produce the observed REE patterns of each subsample are calculated. The extent to which these calculated partition coefficients approximate the accepted equilibrium values indicate the degree of equilibration between each subsample and amphibole.

In the following calculations of REE mineral-mineral partitioning, the REE data for the subsample and amphibole are considered along with the REE data of the constituent cpx mineral. Two versions of the metasomatic process are modeled. The first version is similar to the hypothetical amphibole:garnet pyroxenite example and assumes that the REE completely

equilibrated between the subsample and the original metasomatic liquid prior to crystallization to amphibole. This "equilibrium" version (Fig. 7B) quantifies the relative proportions of amphibole and peridotite subsample and operative partition coefficients involved in the metasomatic process. The second "non-equilibrium" version (Fig. 7C) assumes non- or partial equilibration between the subsample and the amphibole and attempts to define the REE abundance pattern of a metasomatic component that is introduced to the subsamples. The nature of this metasomatic component depends on the mechanism of REE transport during partitioning. If the transport of REE is largely controlled by diffusion as suggested by Harte et al. (1987), this component could be considered an atomic constituent of the peridotite. Regardless of the details of REE transport, the metasomatic component is assumed to have originated from the metasomatic liquid and to have imprinted its REE pattern over the existing subsample pattern. As discussed below, the REE patterns of the metasomatic components are constrained using the REE data of the cpx mineral phases of each subsample.

\section{(A) The Amphibole:wR-1 subsystem - Equilibrium Version}

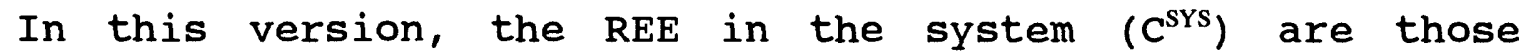
contained in the amphibole-bearing vein and the WR-1 subsample and are assumed to have partitioned freely between these two components during melt introduction and crystallization. The concentration of any REE in the amphibole vein is designated $C^{A M P}$ and the concentration of any REE in the WR-1 subsample is $C^{\mathrm{WR}-1}$. Both sets of concentrations are the analytically determined values. By simple mass balance, the concentration of any REE in this system is : 


$$
\mathrm{x}_{\mathrm{AMP}} \mathrm{C}^{\mathrm{AMP}}+\mathrm{x}_{\mathrm{WR}-1} \mathrm{C}^{\mathrm{WR}-1}=\mathrm{C}^{\mathrm{SYS}} \text {, }
$$

where $x_{A M P}$ and $x_{W R-1}$ are the weight fractions of the amphibole vein and the WR-1 subsample, respectively.

Application of Eqn. 1 yields the expression:

$$
\left[D^{\mathrm{WR}-1} /\left(\mathrm{D}^{\mathrm{WR}-1}+\mathrm{D}^{\mathrm{AMP}}\right)\right] \mathrm{C}^{\mathrm{SYS}} / \mathrm{x}_{\mathrm{WR}-1}=\mathrm{C}^{\mathrm{WR}-1} \text {, }
$$

where $D^{W R-1}$ is the bulk partition coefficient of any REE for the WR-1 peridotite; $D^{A M P}$ is the mineral-melt partition coefficient of any REE for the amphibole vein; $C^{\text {SYS }}$ is the concentration of any REE in the system composed of amphibole plus WR-1 (Eqn. 6); $x_{\text {WR-1 }}$ is the weight fraction of WR-1 involved in the metasomatic process (equivalent to the $x_{W R-1}$ value of Eqn. 6); and $C^{W R-1}$ is the concentration of any REE in the WR-1 subsample.

By substituting the expression for $C^{\text {SYS }}$ given by Eqn. 6 into Eqn. 7, the $C^{\text {sYs }}$ term is eliminated to give:

$$
\frac{D^{\mathrm{WR}-1}}{-\mathrm{D}^{\mathrm{WR}-1}+\mathrm{D}^{\mathrm{AMP}}} \mathrm{C}^{\mathrm{WR}-1}+\frac{\mathrm{X}_{\mathrm{AMP}}}{\mathrm{x}_{\mathrm{WR}-1}} \frac{\mathrm{D}^{\mathrm{WR}-1}}{\mathrm{D}^{\mathrm{WR}-1}+\mathrm{D}^{\mathrm{AMP}}} \mathrm{C}^{\mathrm{AMP}}=\mathrm{C}^{\mathrm{WR}-1} \text {. }
$$

Following the procedure outlined in modeling the garnet pyroxenite, the $D^{\mathrm{WR}-1} /\left(D^{\mathrm{WR}-1}+D^{\mathrm{AMP}}\right)$ ratios for each REE are first estimated using literature values of mineral-melt partition coefficients. The initial estimate for the $D^{\mathrm{WR}-1}$ values are based on a peridotite assemblage composed of $15 \% \mathrm{cpx}$ and $85 \%$ oltopx+spinel, (i.e., $\mathrm{D}^{\mathrm{WR}-1}=0.15 \mathrm{D}^{\mathrm{CPX}}+0.85 \mathrm{D}^{\mathrm{OL}+}$ ) and the $\mathrm{D}^{\mathrm{CPX}}$ and $\mathrm{D}^{\mathrm{OL}+}$ values presented in Table 6A. Although a better estimate of the $\mathrm{D}^{\text {WR-1 }}$ values would include an interstitial amphibole contribution, the initial calculations require only reasonable estimates for the $D$ values. The $D^{A M P}$ values in Table $6 \mathrm{~A}$ are those of Irving and Frey (1984). The estimated values of $D$ ratios are then multiplied by the observed $C^{\text {WR-1 }}$ and $C^{\text {AMP }}$ concentrations as in Eqn. 8 . It is assumed that the first terms in Eqn. 8 are exact and the coefficient of these terms, designated as TOT in Table 6A, is constrained to be 1.0 . The optimal value of $x_{\mathrm{AMP}} / \mathrm{x}_{\mathrm{WR}-1}$, the relative weight fraction of amphibole versus WR-1, is calculated from the set of equations, one for each REE, utilizing MLRA. The matrix of input parameters used in the preliminary calculation of $\mathrm{x}_{\mathrm{AMP}} / \mathrm{x}_{\mathrm{WR}-1}$ together with the results are presented in Table 6A. 


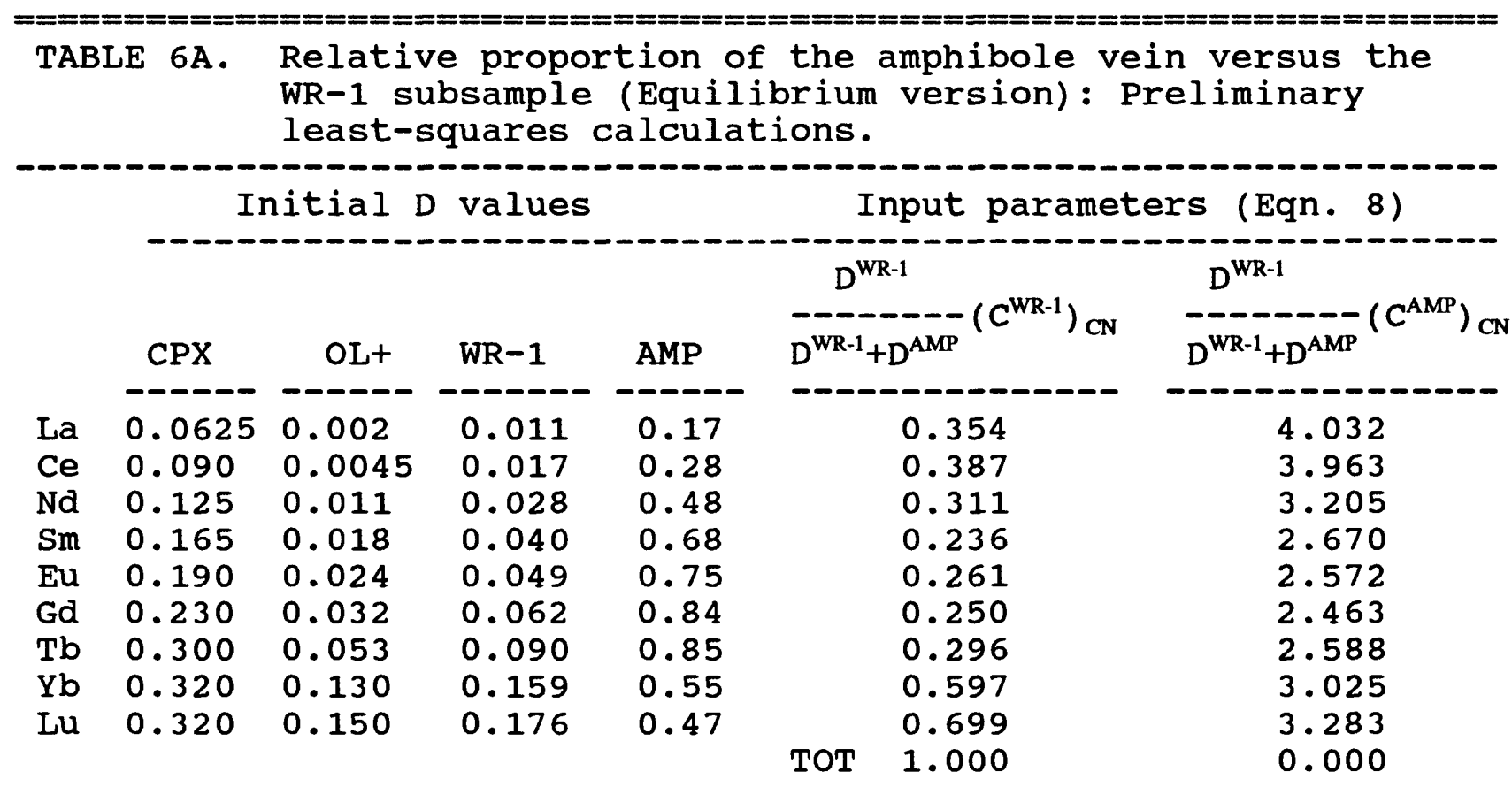

Results

chi square $=12.80$

$$
\mathrm{x}_{\mathrm{AMP}} / \mathrm{x}_{\mathrm{WR}-1}=1.023+-0.148
$$$$
\left(C^{\mathrm{WR}-1}\right)_{\mathrm{CN}} \quad \text { Pct PCt }
$$

\begin{tabular}{crrrr} 
Observed & Calc & \multicolumn{1}{c}{ Diff } & Diff & \multicolumn{1}{c}{ Sig } \\
-0.79 & 4.47 & -1.32 & -29.6 & 10.0 \\
5.64 & 4.43 & -2.21 & -50.0 & 10.0 \\
5.63 & 3.58 & -2.05 & -57.3 & 10.0 \\
4.24 & 2.96 & -1.28 & -43.1 & 10.0 \\
4.26 & 2.88 & -1.38 & -47.0 & 10.0 \\
3.65 & 2.76 & -0.89 & -32.3 & 10.0 \\
3.09 & 2.93 & -0.15 & -5.2 & 10.0 \\
2.67 & 3.67 & 1.00 & 32.7 & 10.0 \\
2.57 & 4.04 & 1.47 & 57.0 & 10.0 \\
1.00 & 0.97 & -0.03 & -3.3 & 5.0
\end{tabular}


The differences between the calculated (by Eqn. 8) and observed $C^{\text {WR-1 }}$ concentrations are minimized by adjusting the original estimated $D^{\mathrm{WR}-1}$ and $\mathrm{D}^{\mathrm{AMP}}$ values and, therefore, optimizing $D^{\mathrm{WR}-1} / \mathrm{D}^{\mathrm{WR}-}$ $\left.{ }^{1}+D^{A M P}\right)$. These differences require $30-50 \%$ higher $D^{\text {WR-1 }}$ values for the LREE and MREE (Fig. 8) in order to produce the observed LREE enrichment in WR-1 and could be interpreted to indicate the effect of interstitial amphibole. The calculations were repeated using the adjusted $D$ values (Table 6B).

The result indicates that roughly equal weight fractions of the amphibole vein and WR-1 peridotite (i.e., $\mathrm{x}_{\mathrm{AMP}} / \mathrm{x}_{\mathrm{WR}-1} \sim 1.0$ ) would have been involved in the re-equilibration and exchange of the REE, if the metasomatic partitioning process had been confined to this subsystem. This ratio corresponds roughly to the amount of intruding amphibole-bearing liquid relative to the original peridotite subsample that was metasomatized and not to a infiltrated amphibole/wallrock ratio that is calculated from a simple mixing model (see Fig. 7). Because the adjusted partition coefficients for $\mathrm{D}^{\mathrm{AMP}}$ and $\mathrm{D}^{\mathrm{WR}-1}$ are not significantly different from equilibrium values, it is suggested that the amphibole:WR-1 subsystem represents equilibrium partitioning of the REE. The REE concentrations of the original amphibole-bearing liquid in this system $\left(C^{\mathrm{L} 1}\right)$ are estimated from the equation:

$$
\mathrm{C}^{\mathrm{AMP}}+\mathrm{x}_{\mathrm{WR}-1} / \mathrm{x}_{\mathrm{AMP}}\left(\mathrm{C}^{\mathrm{WR}-1}-\mathrm{C}^{\mathrm{WR}-4}\right)=\mathrm{C}^{\mathrm{L}}
$$

which is analogous to Eqn. 5. The results are presented in Table 7 .

\section{(B) Further constraints on solutions based on cpx separates from WR-1}

The results of the partitioning model using the REE data of the $\mathrm{cpx}$ separates from WR-1 and the host subsample indicate that additional constraints can be placed on the choice of operative D values for amphibole and WR-1. The initial form of Eqn. 1 used to account for the REE concentrations of the clinopyroxene (CPX-1) in WR-1 is given by the following expression:

$$
\left[D^{\mathrm{CPX}-1} /\left(\mathrm{D}^{\mathrm{CPX}-1}+\mathrm{D}^{\mathrm{OTHER}}\right)\right] \mathrm{C}^{\mathrm{WR}-1} / \mathrm{x}_{\mathrm{CPX}-1}=\mathrm{C}^{\mathrm{CPX}-1} \text {, }
$$

where $D^{\text {CPX-1 }}$ is the mineral-melt partition coefficient of any REE for the clinopyroxene in WR-1; $D^{\text {OTHER }}$ was assumed to be the sum of the mineral-melt partition coefficients of any REE for the other mineral phases in WR-1, excluding $\mathrm{Cpx} ; \mathrm{C}^{\mathrm{WR}-1}$ is the concentration of any REE in WR-1; $x_{\mathrm{CPX}-1}$ is the weight fraction of $\mathrm{CPX}-1$ in $\mathrm{WR}-1$; and $C^{\text {CPX-1 }}$ is the concentration of any REE in the CPX-1 separate. 


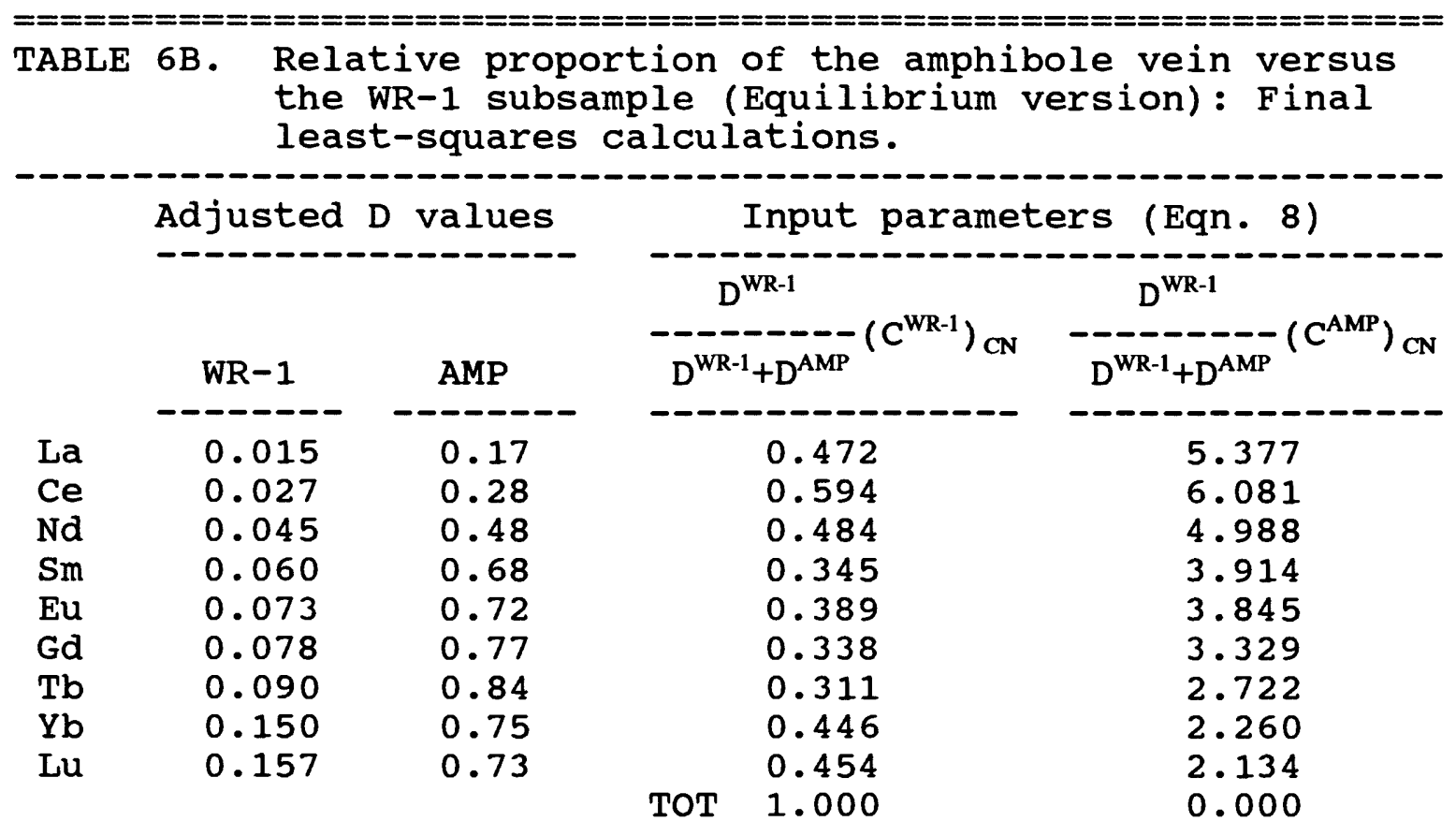

Results

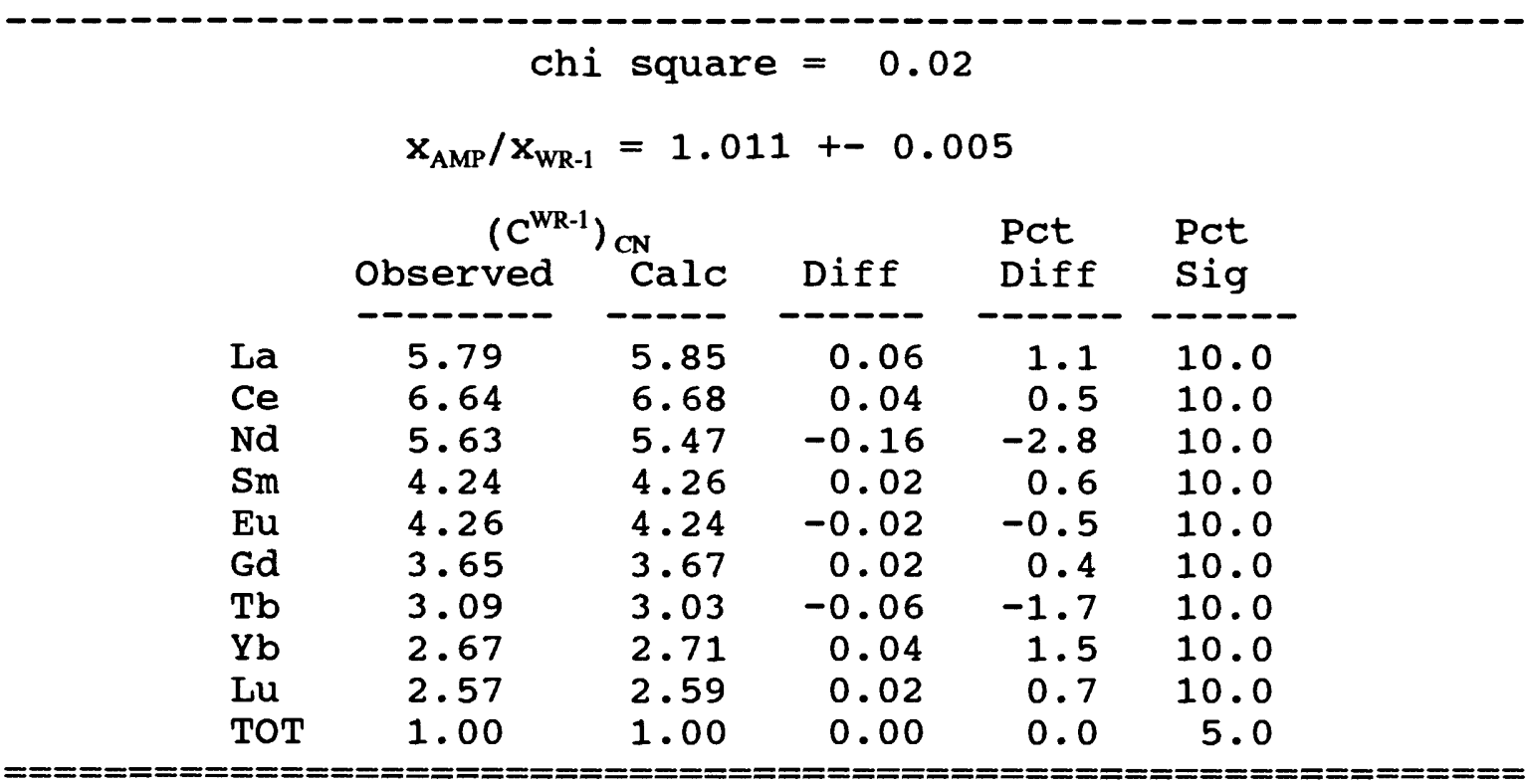




\begin{tabular}{|c|c|c|c|c|c|}
\hline \multirow[t]{3}{*}{ TABLE } & \multicolumn{5}{|c|}{$\begin{array}{l}\text { Relative } D \text { values for } W R-1 \text { and amphibole: } \\
\text { Constrained from } D \text { values for } C P X-1 \text { that provide } \\
\text { the best match to } C P X-1 \text { concentrations. }\end{array}$} \\
\hline & \multicolumn{3}{|c|}{ Final D Values } & \multicolumn{2}{|c|}{$\left(C^{C P X-1}\right)_{C N}$} \\
\hline & $\begin{array}{r}\text { WR-1 } \\
\text { (1) }\end{array}$ & $\begin{array}{c}\text { AMP-1 } \\
\text { (2) }\end{array}$ & $\begin{array}{c}C P X-1 \\
\text { (1) }\end{array}$ & Observed & $\begin{array}{c}\mathrm{Calc} \\
(3)\end{array}$ \\
\hline $\mathrm{La}$ & 0.015 & 0.17 & 0.0625 & 21.87 & 21.71 \\
\hline $\mathrm{Ce}$ & 0.027 & 0.28 & 0.090 & 23.49 & 23.76 \\
\hline $\mathrm{Nd}$ & 0.045 & 0.48 & 0.125 & 17.25 & 19.28 \\
\hline $\mathrm{Sm}$ & 0.062 & 0.70 & 0.165 & 13.62 & 14.32 \\
\hline $\mathrm{Eu}$ & 0.073 & 0.75 & 0.190 & 13.38 & 14.30 \\
\hline Gd & 0.083 & 0.82 & 0.230 & 12.30 & $(12.36)$ \\
\hline $\mathrm{Tb}$ & 0.095 & 0.84 & 0.285 & 10.85 & 10.76 \\
\hline $\mathrm{Yb}$ & 0.125 & 0.63 & 0.380 & 9.71 & 9.33 \\
\hline $\mathrm{Lu}$ & 0.130 & 0.60 & 0.380 & 9.29 & 8.91 \\
\hline
\end{tabular}

1. Partition coefficients for WR-1 and CPX-1 using Eqn. 10, measured $\mathrm{C}^{\mathrm{WR}-1}$ and $\mathrm{C}^{\mathrm{CPX}-1}$ concentrations, and $\mathrm{x}_{\mathrm{CPX}-1}=0.215$.

2. Partition coefficients for amphibole using Eqn. 8 and

D values for WR-1 of this table.

3. Calculated CPX-1 concentrations using Eqn. 10. The Gd concentration is calculated using an interpolated Gd value for WR-1.

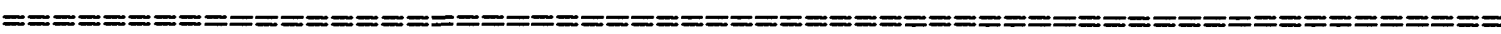

Using this equation and the measured $C^{\text {WR-1 }}$ and $C^{\text {CPX-1 }}$ concentrations, a set of $\mathrm{D}^{\mathrm{CPX}-1}, \mathrm{D}^{\text {OTHER }}$ and $\mathrm{x}_{\mathrm{CPX}-1}$ values are calculated that best account for the observed $C^{C P X-1}$ abundances. This approach was taken because of the uncertainties in the modal compositions and, therefore, the weight fractions of $\mathrm{cpx}\left(\mathrm{x}_{\mathrm{CPX}-1}\right)$ in the subsamples (Nielson et al., 1993). Nevertheless, the value of $x_{C P x}$ $1=21.5 \%$ calculated from Eqn. 10 compares favorably to the counted cpx modes of 21.0-22.1\% (Nielson, et al., 1993). These calculations indicate that $D^{\text {OTHER }}$ values are virtually identical to the $D^{W R-1}$ values obtained from modeling the amphibole:WR-1 subsystem. The equivalence of $D^{\text {OTHER }}$ and $D^{\text {WR-1 }}$ values is interpreted to indicate 


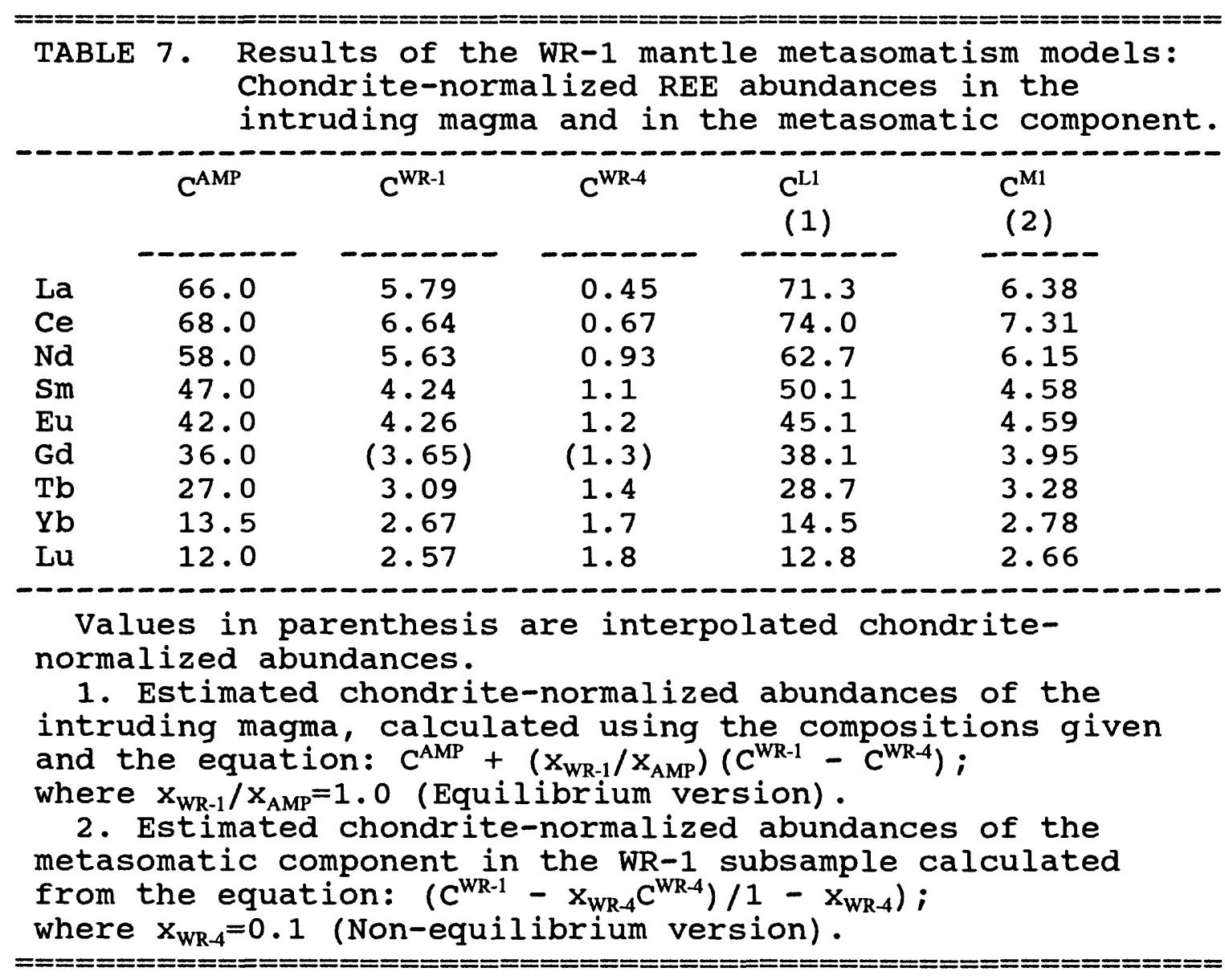

that individual cpx minerals are competing with the entire surrounding modal mineral assemblage (ol+ and $\mathrm{cpx}$ ) to partition the REE. On the basis of this conclusion, the $D^{O T H E R}$ values required for a proper match to clinopyroxene concentrations in the CPX-1:WR-1 model (Eqn. 10) are substituted for $D^{\text {WR-1 }}$ values in Eqn. 8 to derive the set of $D^{A M P}$ values for the amphibole:WR-1 model (Table 6C). The initial and final set of $D$ values for $A M P-1, W R-1$ and $C P X-1$ are compared in Fig. 8. The criteria of internal consistency based onthe equivalence of $D^{\text {OTHER }}$ and $D^{\text {WR }}$ values is applied in all subsequently modeled subsystems. 


\section{(C) The Amphibole:WR-1 subsystem - Non-equilibrium version}

In this version, the REE in the system ( ${ }^{S Y S}$ ) are defined to be contained in the amphibole vein (C ${ }^{\text {AMP }}$ ) and in a metasomatic component $\left(\mathrm{C}^{\mathrm{M} 1}\right)$ that was originally in the metasomatic liquid and has been introduced to the WR-1 subsample. As discussed above, the metasomatic component (M) may represent a diffusion-transported atomic constituent of the peridotite. The REE concentrations in this system are:

$$
\mathrm{x}_{\mathrm{AMP}} \mathrm{C}^{\mathrm{AMP}}+\mathrm{x}_{\mathrm{M} 1} \mathrm{C}^{\mathrm{M} 1}=\mathrm{C}^{\mathrm{SYS}} \text {, }
$$

where $x_{A M P}$ and $x_{M 1}$ are the weight fractions of the amphibole vein and of the peridotite that contains the metasomatic component. This model differs from the equilibrium version in that only the REE carried by the original intruding amphibole-bearing liquid are considered to be available to partition. This non-equilibrium version was considered because equilibrium conditions were almost certainly not attained between the amphibole vein and the more distant whole-rock subsamples. This approach also enables the REE composition of the metasomatic component in each subsample to be estimated.

The concentration of any REE in the metasomatic component of WR-1 is described by the same equation (Eqn. 7) that was used for the equilibrium version of partitioning between the amphibole vein and subsample:

$$
\left[D^{\mathrm{WR}-1} /\left(D^{\mathrm{WR}-1}+\mathrm{D}^{\mathrm{AMP}}\right)\right] \mathrm{C}^{\mathrm{SYS}} / \mathrm{X}_{\mathrm{M} 1}=\mathrm{C}^{\mathrm{M} 1} \text {. }
$$

The equation for calculating the relative weight fractions of amphibole and the peridotite containing the metasomatic component is analogous to Eqn. 8:

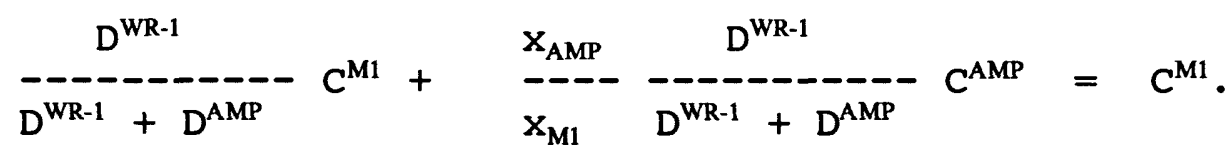

The procedure used to estimate $C^{M 1}$ abundances is based on the assumption that any change in $\mathrm{C}^{\mathrm{WR}-1}$ abundances as a result of the metasomatic process would be reflected in the clinopyroxene abundances (i.e., $C^{\mathrm{CPX}-1}$ ). The sensitivity of cpx to metasomatic alteration is evident in the positive Eu anomaly in the REE pattern for CPX-1 (Fig. 5). The model of REE partitioning between CPX-1 and the WR-1 subsample discussed in the preceding section is used to constrain $\mathrm{C}^{\mathrm{M} 1}$.

Assuming that $\mathrm{C}^{\mathrm{CPX}-1}$ will respond to changes in $\mathrm{C}^{\mathrm{WR}-1}$ during metasomatism, Eqn. 10 can be rewritten by substituting $\mathrm{C}^{\mathrm{M} 1}$ for $\mathrm{C}^{\mathrm{WR}-1}$ and $C^{\text {CPX-1M }}$ for $C^{\text {CPX-1 }}$, where $C^{\text {CPX-1M }}$ is the metasomatic component introduced to the $\mathrm{cpx}$ separate. The expression for $\mathrm{C}^{\mathrm{M} 1}$ (Eqn. 12) is substituted into the recast Eqn. 10 to give: 


$$
\frac{\mathrm{D}^{\mathrm{WR}-1}}{\mathrm{D}^{\mathrm{WR}-1}+\mathrm{D}^{\mathrm{AMP}}} \frac{\mathrm{D}^{\mathrm{CPX} 1}}{\mathrm{D}^{\mathrm{CPX1}}+\mathrm{D}^{\mathrm{WR}-1}} \frac{\mathrm{C}^{\mathrm{SYS}}}{\mathrm{X}_{\mathrm{M} 1} \mathrm{x}_{\mathrm{CPX}}}=\mathrm{C}^{\mathrm{CPX}-1 \mathrm{M}},
$$

and this equation is used as follows to constrain $\mathrm{C}^{\mathrm{M}}$ :

(1) The REE concentrations in the metasomatic component $\left(\mathrm{C}^{\mathrm{M} 1}\right)$ are calculated as the difference between the observed REE concentrations in WR-1 and a fraction of the original REE concentrations, the latter approximated by the concentrations in the unaltered subsample, WR-4. The calculations are not appreciably different if the WR-5 concentrations are used instead of the WR-4 concentrations. The equation used is:

$$
\left(C^{\mathrm{WR}-1}-\mathrm{x}_{\mathrm{WR}-4} \mathrm{C}^{\mathrm{WR}-4}\right) /\left(1-\mathrm{x}_{\mathrm{WR}-4}\right)=\mathrm{C}^{\mathrm{M} 1}
$$

which is derived from mass balance; $\mathrm{x}_{\mathrm{WR} 4} \mathrm{C}^{\mathrm{WR} 4}+\left(1-\mathrm{x}_{\mathrm{WR} 4}\right) \mathrm{C}^{\mathrm{M} 1}=\mathrm{C}^{\mathrm{WR} 1}$. BY varying the assumed fractional contribution $\left(x_{\mathrm{WR}-4}\right)$ of unaltered end member WR-4 to the mix, different REE abundance patterns are calculated for the metasomatic component. The initial value of $x_{W R-4}$ was arbitrarily set at 0.1 and subsequent values were increased in increments of 0.1 .

(2) Using the $\mathrm{C}^{\mathrm{M} 1}$ abundances determined from Eqn. 15 for a given $x_{\text {WR-4 }}$ value, $D^{\text {WR-1 }}, D^{A M P}, x_{A M P}$ and $x_{M 1}$ are obtained by least-squares calculations utilizing Eqn. 13 (refer to the equilibrium version for the details). The $c^{\text {sys }}$ abundances are calculated using Eqn. 11, the $C^{\mathrm{AMP}}$ and $\mathrm{C}^{\mathrm{M} 1}$ concentrations and the preferred values of $x_{A M P}$ and $x_{M 1}$.

(3) Using these $C^{S Y S}$ abundances, the REE concentrations of the metasomatic component added to the $\mathrm{cpx}\left(\mathrm{C}^{\mathrm{CPX}-1 \mathrm{M}}\right)$ is calculated using Eqn. 14 .

(4) Because it is assumed that the fractional REE contribution of the original cpx abundances to the observed cpx composition is the same as that for the whole-rock subsample (i.e., $\left.x_{\mathrm{WR}-4}=\mathrm{x}_{\mathrm{CPX}-4}\right)$, then the $C^{\mathrm{CPX}-1}$ concentrations for the corresponding value of $x_{\mathrm{WR}-4}$ are estimated using the following equation:

$$
\mathrm{x}_{\mathrm{WR}-4} \mathrm{C}^{\mathrm{CPX}-4}+\left(1-\mathrm{x}_{\mathrm{WR}-4}\right) \mathrm{C}^{\mathrm{CPX}-1 \mathrm{M}}=\mathrm{C}^{\mathrm{CPX}-1} \text {. }
$$

(5) The agreement between these estimated $C^{\text {CPX-1 }}$ concentrations and the observed REE abundances in cpx separates is optimized to constrain the value of $x_{\mathrm{WR}-4}$ and, therefore, the $\mathrm{c}^{\mathrm{Ml}}$ values.

The REE composition of the metasomatic addition ( ${ }^{\mathrm{M} 1}$ ) to the WR-1 subsample is presented in Table 7, and chondrite-normalized values are plotted in Fig. 9. A value of $x_{\mathrm{WR}-4}=0.1$ produced a $R E E$ abundance pattern for this metasomatic component that best accounted for the REE abundance pattern of $\mathrm{cpx}$; the estimated $\mathrm{C}^{\mathrm{CPX}-1}$ abundances are within $\pm 2 \%$ of the observed abundances. Although the $\mathrm{D}^{\mathrm{WR}-1}$ and $\mathrm{D}^{\mathrm{AMP}}$ values obtained in these calculations are similar to the values of the equilibrium version (Eqn. 7), in subsequent calculations for other subsamples, the plots of $D$ values for the REE determined from the non-equilibrium version were more 
consistent with plots of experimentally determined values. For example, in the amphibole:WR-2 subsystem, the pattern of partition coefficients plotted for the amphibole based on the equilibrium version was S-shaped, requiring higher D values for La than for Ce. The relative $D$ values presented in the following subsystem calculations, therefore, are those that best accounted for the REE concentrations of amphibole, the whole-rock subsample and cpx from each subsample based on the non-equilibrium version.

\section{(D) The Amphibole:WR-2 subsystem (both versions)}

The partition coefficients used in the preliminary calculations of REE partitioning in this subsystem are the adjusted $D$ values obtained in the calculation in the amphibole:WR-1 subsystem (Table 6C). The calculations of REE partitioning between CPX-2 and WR-2 indicate that the middle REE (MREE) concentrations in WR-2 are too low to produce the MREE concentrations in CPX -2 . The MREE concentrations in WR-2 are modified to better account for the REE pattern of $\mathrm{CPX}-2$. This correction is equivalent to the addition of about $3 \% \mathrm{cpx}$ to the split of WR-2 analyzed by INAA.

The equilibrium version calculations for the amphibole:WR-2 subsystem are presented in Tables 8 and 9. As in earlier calculations, the $D^{\text {WR-2 }}$ values are constrained by $D^{\text {CPX-2 }}$ values to produce the best match with the observed REE concentrations of CPX2 separates. These $D^{W R-2}$ values, in turn, require the partition coefficients of the amphibole vein ( $D^{\mathrm{AMP}-2}$ ) to be adjusted to account for the observed REE concentrations of WR-2. The adjusted $\mathrm{D}^{\mathrm{AMP}-2}$ values are considerably lower for the HREE compared to the $D^{A M P}$ values in the WR-1 subsystem. The weight ratio of amphibole vein to peridotite $\left(x_{\mathrm{AMP}} / \mathrm{x}_{\mathrm{WR}-2}\right)$ calculated from this model is $\sim 0.33$. The significance of the lower "apparent" $\mathrm{D}^{\mathrm{AMP}-2}$ values and the $\mathrm{x}_{\mathrm{AMP}} / \mathrm{x}_{\mathrm{WR}-2}$ ratio are discussed below. The REE composition of the intruding liquid $\left(\mathrm{C}^{\mathrm{L} 2}\right)$ is estimated using Eqn. 9 and given in Table 9. The REE composition of the metasomatic component ( $\mathrm{C}^{\mathrm{M} 2}$ ) introduced to the WR-2 sample, as calculated from the nonequilibrium version, is given in Table 9 and depicted in Fig. 9. The REE abundance pattern of this component was estimated using the appropriate form of Eqn. 15. A value of $x_{\mathrm{WR}-4}=0.2$ best accounted for the metasomatic contribution of REE to the CPX-2 separate. 


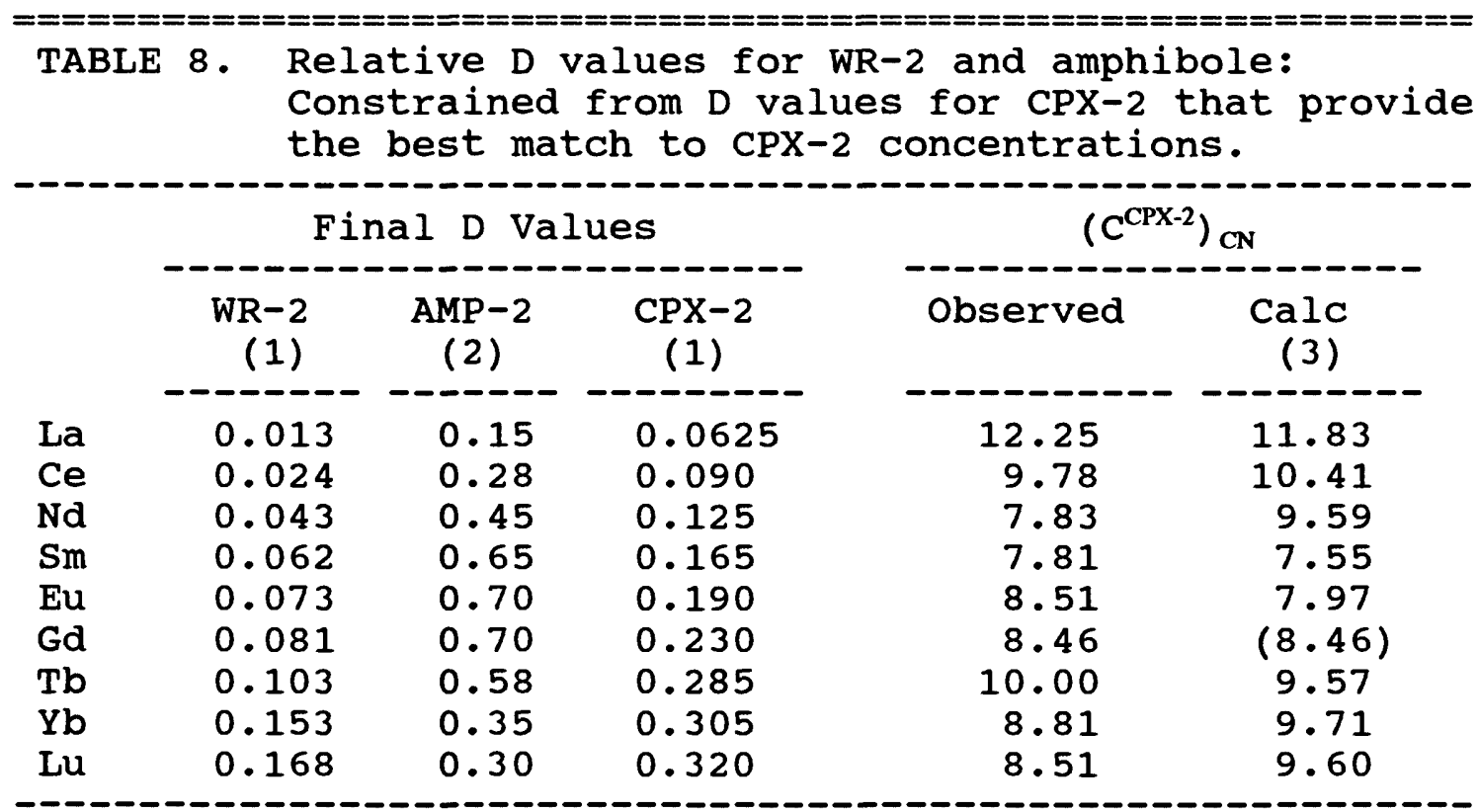

1. Partition coefficients for $\mathrm{WR}-2$ and $\mathrm{CPX}-2$ using Eqn. 10, modified $\mathrm{C}^{\mathrm{WR}-2}$ and measured $\mathrm{C}^{\mathrm{CPX}-2}$ concentrations,

and $\mathrm{x}_{\mathrm{CPX}-2}=0.135$.

2. Partition coefficients for amphibole using Eqn. 8 and

$D$ values for WR- 2 of this table.

3. Calculated CPX-2 concentrations using Eqn. 10. The Gd concentration is calculated using an interpolated Gd value for WR-2 .

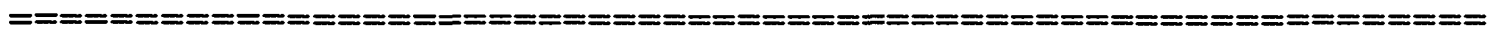

\section{(E) The Amphibole:WR-3 subsystem (both versions)}

In modeling this subsystem, the REE abundances of WR-3 are also modified to be more consistent with the observed $\mathrm{CPX}-3$ composition. This correction is equivalent to the addition of about $2 \% \mathrm{cpx}$ to the WR-3 split. 


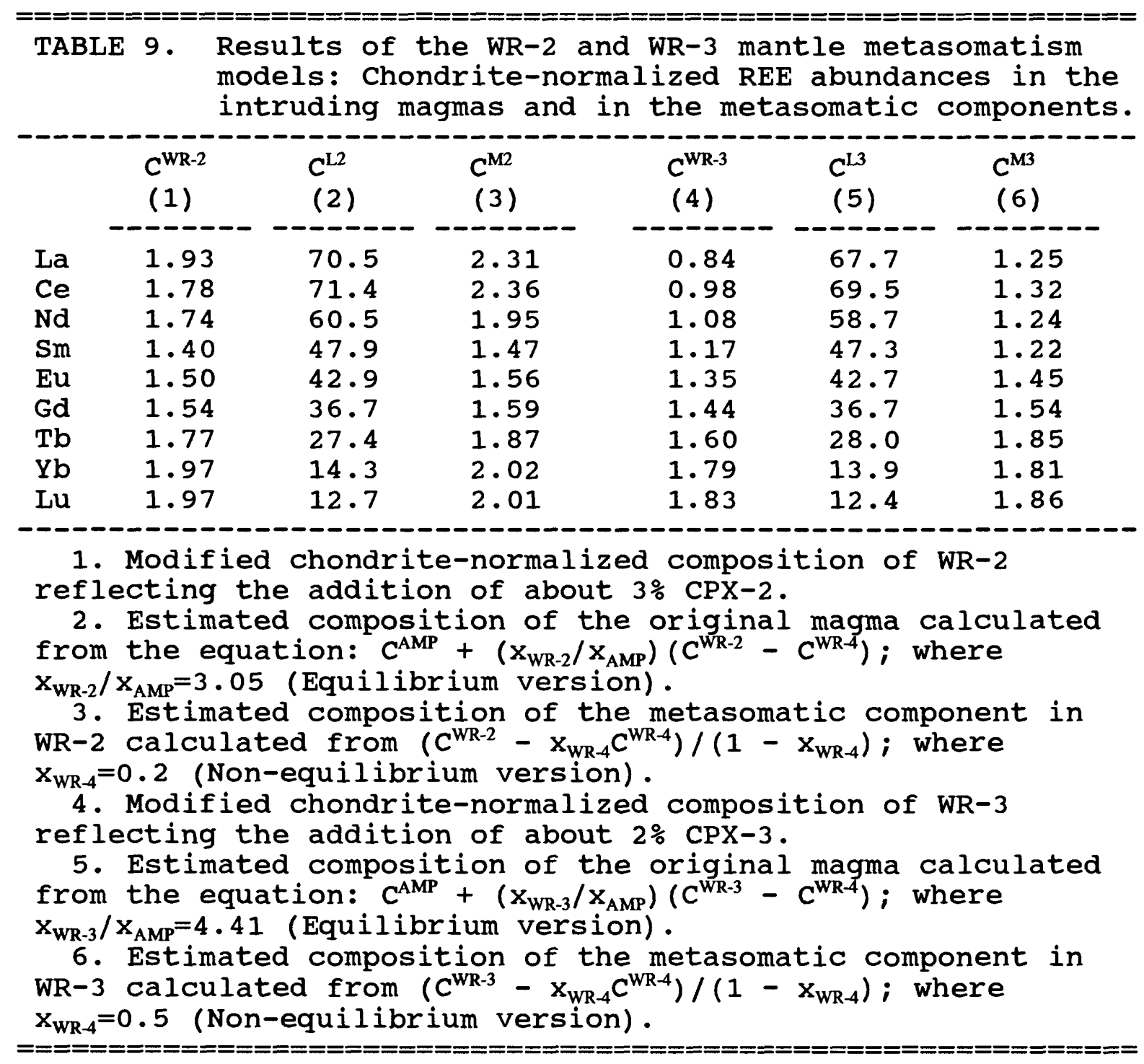

The relative, adjusted REE partition coefficients for the whole-rock, amphibole and cpx phases in this subsystem given in Table 10 are the most internally consistent set of values derived from the amphibole:WR-3 and CPX-3:WR-3 partitioning models. The adjusted $D^{\mathrm{WR}-3}$ values for all the REE are consistently lower than similar values calculated for previous subsamples (WR-2 and WR-1). The "apparent" $D^{\text {AMP-3 }}$ values are again required to be lower, not onlyfor the HREE, but also for the MREE. The $x_{\text {AMP }} / x_{\text {WR-3 }}$ ratio determined for this subsystem is about 0.23 and the intruding liquid composition $\left(C^{\mathrm{L} 3}\right)$ calculated from Eqn. 9 is given in Table 9 . 


\begin{tabular}{|c|c|c|c|c|c|}
\hline \multirow[t]{3}{*}{ TABI } & \multicolumn{5}{|c|}{$\begin{array}{l}\text { 10. Relative } D \text { values for } W R-3 \text { and amphibole: } \\
\text { Constrained from } D \text { values for } C P X-3 \text { that provid } \\
\text { the best match to } C P X-3 \text { concentrations. }\end{array}$} \\
\hline & \multicolumn{3}{|c|}{ Final D Values } & \multicolumn{2}{|c|}{$\left(\mathrm{C}^{\mathrm{CPX}-3}\right)_{\mathrm{CN}}$} \\
\hline & $\begin{array}{r}\text { WR-3 } \\
(1)\end{array}$ & $\begin{array}{c}A M P-3 \\
(2)\end{array}$ & $\begin{array}{c}C P X-3 \\
(1)\end{array}$ & Observed & $\begin{array}{r}\mathrm{Calc} \\
(3)\end{array}$ \\
\hline La & 0.011 & 0.15 & 0.055 & 4.95 & 5.19 \\
\hline $\mathrm{Ce}$ & 0.018 & 0.28 & 0.080 & 5.49 & 5.93 \\
\hline $\mathrm{Nd}$ & 0.030 & 0.37 & 0.125 & 6.72 & 6.45 \\
\hline $\mathrm{Sm}$ & 0.042 & 0.38 & 0.165 & 7.24 & 6.91 \\
\hline $\mathrm{Eu}$ & 0.048 & 0.375 & 0.190 & 8.38 & 7.98 \\
\hline Gd & 0.059 & 0.365 & 0.230 & 8.46 & $(8.25)$ \\
\hline $\mathrm{Tb}$ & 0.083 & 0.33 & 0.285 & 9.36 & 9.17 \\
\hline Yb & 0.110 & 0.205 & 0.305 & 8.76 & 9.74 \\
\hline $\mathrm{Lu}$ & 0.110 & 0.175 & 0.320 & 8.36 & 10.00 \\
\hline
\end{tabular}

1. Partition coefficients for $W R-3$ and $C P X-3$ using Eqn. 10, modified $\mathrm{C}^{\mathrm{WR}-3}$ and measured $\mathrm{C}^{\mathrm{CPX}-3}$ concentrations, and $\mathrm{x}_{\mathrm{CPX}-3}=0.135$.

2. Partition coefficients for amphibole using Eqn. 8 and $D$ values for WR-3 of this table.

3. Calculated CPX-3 concentrations using Eqn. 10. The Gd concentration is calculated using an interpolated Gd value for WR-3.

The REE pattern of the metasomatic component $\left(\mathrm{C}^{\mathrm{M} 3}\right)$ added to WR3 is plotted in Fig. 9. This pattern was estimated using a form of Eqn. 15 and an optimum value of $x_{\mathrm{WR}-4}=0.5$.

\section{THE INTEGRATED AMPHIBOLE:PERIDOTITE MODEL}

The integrated amphibole:peridotite model is used to estimate the proportions of metasomatized peridotite and amphibole-bearing vein in the composite xenolith $\mathrm{BA}-2-1$. In previous calculations using subsample data, the derived values of $x_{\text {amp }} / x_{\text {subsample }}$ that produced the best match with the observed REE compositions were for that particular subsample only; all other subsample compositions were ignored. In order to obtain an overall $x_{\text {amp }} / x_{\text {peridotite }}$ ratio, the entire metasomatized portion of the xenolith must be considered. Therefore, it is postulated that the average REE composition of the three enriched subsamples (WR-1, WR-2 and WR-3) would be the composition produced if the effects of metasomatism were homogeneously distributed throughout this enriched portion of the peridotite. The method of calculation is identical to that used 
for the individual subsamples, utilizing a form of Eqn. 8 and this average composition. The initial partition coefficients used for amphibole and peridotite whole-rock are also the average $D$ values derived from the three subsystem calculations. The results of these calculations indicate that REE partitioning has occurred between the amphibole-bearing vein and a volume of peridotite that is approximately two times the weight of the original magma, under the conditions of metasomatism for the Dish Hill xenolith.

\section{DISCUSSION}

Two key features of mineral-mineral partitioning permit this model to conform with observed compositional and physical characteristics of metasomatic rocks more than other proposed models of mantle metasomatism. Because mineral-mineral partitioning is a diffusion-driven process occurring at the atomic level and is inferred to occur among major elements, metasomatic enrichment by this process can take place without any textural or modal evidence of metasomatism and has the potential to account for variable mineral and major element compositions, including the enrichment of $\mathrm{Fe}, \mathrm{Ti}$ and $\mathrm{Al}$ in minerals contained in peridotite wallrocks.

Although simple mixing models produce REE abundance patterns that are generally similar to those observed in these rocks, variations in mineral and major element compositions cannot be explained. For example, interstitial amphibole in the WR-4 and WR5 subsamples of the Dish Hill xenolith is pargasitic in composition, in contrast to the kaersutitic composition of the vein amphibole. The transition amphibole compositions found in the WR1, WR-2 and WR-3 subsamples, however, are not simple mixtures of the two (Wilshire et al., 1988). Such compositionally distinct secondary-mineral and glass compositions from the vein and wallrock portions of xenoliths are common (Nielson and Noller, 1987; Liang and Elthon, 1990) and provide additional evidence that the metasomatic process is more complex than simple mixing.

The stepwise mass balance and re-equilibration model presented by Liang and Elthon (1990) may allow for variable mineral compositions; however, the predicted change in REE contents with distance from the vein is not consistent with the variations observed in the Dish Hill xenolith. This re-equilibration model calculates the effect on REE contents in wallrocks by an infiltrating melt, which differentiates and subsequently reequilibrates with different portions of mantle wallrock. Because the melt fractionates as it infiltrates the wallrock, different mineral compositions are expected to be produced. Nevertheless, the model suggests that REE concentrations initially increase in the wallrock with increasing distance from the vein until reaching a maxima, then decrease. These trends are not evident in the $\mathrm{Ba-2-1}$ xenolith, although the scale on which these variations occur in the re-equilibration model is not known.

The disequilibrium melting model of Prinzhofer and Allegre (1985) and the chromatographic column model of Navon and stolper 
(1987) have been proposed to explain U-shaped REE patterns in mantle peridotites. The weaknesses of these two models have been discussed by song and Frey (1989). The disequilibrium melting model requires mantle rocks to have very low initial REE concentrations and/or low bulk D values (e.g., dunites), and cannot generate LREE contents in the residue that are greater than those in the source. The chromatographic column model requires that an REE-rich ascending melt develop a wide range of REE patterns as a function of depth. To produce these various U-shaped patterns in peridotite xenolith, the xenoliths must be equilibrium with the magma at particular mantle locations. In the mineral-mineral partitioning model, specific magma and wallrock compositions and mantle locations are not required. While it is proposed that REE partitioning depends on these compositions, in addition to the time-temperature-pressure conditions of the process, it is the localized variations in these parameters that produce the observed REE patterns in the wallrocks. For example, the differences in the relative affinity between the minerals crystallizing from a magma and the minerals in the wallrock to partition the REE will determine the abundance pattern in peridotites. The initial emplacement temperature and cooling time of the magma influence these affinities and, therefore, the extent of enrichment in the wallrock at increasing distance from the contact. The operative partition coefficients are a measure of the affinities in the mineral-mineral partitioning process and indicate the degree of equilibration between the melt and wallrock.

In the Dish Hill composite peridotite-hornblendite, the wallrock within $1 \mathrm{~cm}$ of the amphibole-bearing vein equilibrated most completely with the introduced magma on the basis of the observation that the REE distribution within the WR-1 subsample can be explained by applying equilibrium partition coefficients. At increasing distance from the contact $(2-5 \mathrm{~cm})$, the partition coefficients required to account for the REE abundances in the peridotite are in poorer agreement with accepted equilibrium values. This suggests that the approach to equilibrium is kinetically hindered. Given sufficiently long times at elevated temperatures, it is conceivable that equilibrium partitioning of the REE would prevail over a larger mantle volume (i.e., at greater distances from the vein). In this case, a REE abundance pattern identical to that of $W R-1$ would be more widespread throughout the peridotite wallrock; only the absolute concentrations would be lower. Calculations based on the REE data would quantify the expected increase in the weight fraction of peridotite relative to the intruding magma. This effect is mimicked by the decrease in the calculated $x_{\text {amp }} / x_{\text {subsample }}$ ratios in successive amphibole:whole-rock models (i.e., $x_{\text {amp }} / x_{\text {subsample }}$ decreases from 1.0 in the amphibole:WR-1 subsystem to 0.23 in the amphibole:WR-3 subsystem).

Because the sets of REE partition coefficients from each subsystem (Tables 6C, 8 and 10) are relative values, D values for any element within a subsystem or for all elements in the subsystem can be mathematically adjusted without affecting the results. On 
the basis of the bulk compositions and inferred partitioning relationships among the whole-rock subsamples, some of the REE partition coefficients are adjusted to be consistent with these effects (Fig. 10). Specifically, all REE partition coefficients for WR-1, AMP-1 and CPX-1 were increased by about $10 \%$, and the values of $\mathrm{Tb}, \mathrm{Yb}$ and $\mathrm{Lu}$ for $\mathrm{WR}-2, \mathrm{AMP}-2$ and $C P X-2$ were decreased by 10\%. The higher D values for the AMP:WR-1 subsystem primarily account for the differences in the modal abundance of cpx in the WR-1 and WR-2 subsamples (i.e., $21.5 \%$ versus $13.5 \%$, respectively), but also reflect higher $D$ values expected for AMP-1 than for AMP-2 on the basis of partitioning model (i.e., the apparent $D$ values for amp are inferred to decrease with increasing distance from the vein). Values of $\mathrm{Tb}, \mathrm{Yb}$ and $\mathrm{Lu}$ for $\mathrm{WR}-3, \mathrm{AMP}-3$ and $\mathrm{CPX}-3$ were also decreased by $10 \%$, because $D$ values for $C P X-3$ are assumed to be identical to the $\mathrm{CPX}-2$ values.

on the scale of an individual clinopyroxene grain, the partitioning of the REE into surrounding minerals depends on the size and abundance of minerals immediately enclosing the cpx. In rocks composed of three or more uniformly distributed mineral phases that are similar in size and modal proportion (e.g., garnet pyroxenite), individual cpx grains are surrounded by a similar assemblage of minerals. The partitioning of REE in cpx is accounted for by a model that assumes similarity of REE partitioning at all scales (i.e., equal weighting of the affinity of each mineral to partition the REE). In contrast, in rocks that contain minerals of different size and modal proportion (e.g., lherzolites), REE partitioning in cpx is better described by a model based on the bulk modal abundance of minerals (i.e., weighting of the affinity of other minerals to partition the REE according to their modal proportions). Collectively, the REE composition of $\mathrm{cpx}$ separates in the studied peridotite appears to be influenced by a mineral assemblage that mimics the whole-rock mode. The similarity in REE abundance patterns between some cpx separates from pyroxene veins and their host peridotites as reported by Song and Frey (1989) support this interpretation. In these composite xenoliths, comparable REE patterns in cpx minerals contained in both the vein and peridotite are expected to be produced if REE partitioning into each $\mathrm{cpx}$ is influenced by the same whole-rock mineral assemblage.

\section{CONCLUSIONS}

The partitioning of REE among coexisting minerals in a crystalline rock is a more complex function of the mineral-melt partition coefficients than was previously considered. An empirical equation is devised that expresses the REE concentrations in a given mineral as a function of (1) the relative partitioning of the mineral to the overall partitioning of $R E E$ in the rock, expressed as $D^{\mathrm{MIN}} /$ sumD, and (2) the weight fraction of the mineral. The concept that REE partitioning among coexisting minerals is a function of the mineral assemblage successfully accounts for the 
range in abundance ratios found in coexisting mineral pairs. Calculations using the empirical equation and the REE concentrations of the constituent minerals can be used to estimate the weight fractions of minerals in a rock.

An alternate application that is stressed in this paper is to explain the observed partitioning of the REE between peridotite and an adjoining amphibole-bearing magma in the BA-2-1 sample. The REE abundance patterns in different subsamples of the composite Dish Hill xenolith are shown to be functions of (1) contrasting abilities of the peridotite and magma to partition the REE, expressed as $D^{\mathrm{WR}} /\left(D^{\mathrm{WR}}+D^{\mathrm{AMP}}\right)$ and (2) the relative proportions of the magma and the peridotite. It is inferred that the initial temperature and cooling time of the melt is also important, but these factors cannot be quantified from this model. REE partitioning between melt and peridotite as a function of these parameters successfully accounts for the abundance patterns found in these rocks. Calculations using the empirical equation and the REE concentrations of the melt and peridotite can be used to estimate the weight fractions of the components that are metasomatized. The extent of LREE-enrichment quantifies the timetemperature conditions of the metasomatic process.

\section{ACKNOWLEDGEMENTS}

I especially thank Jane Nielson and Howard Wilshire for inviting me to participate in their study of the Dish Hill xenolith. This manuscript was significantly improved from many fruitful discussions with Jane. Robert Zielinski also provided many useful comments and suggestions during the preparation of this manuscript. 


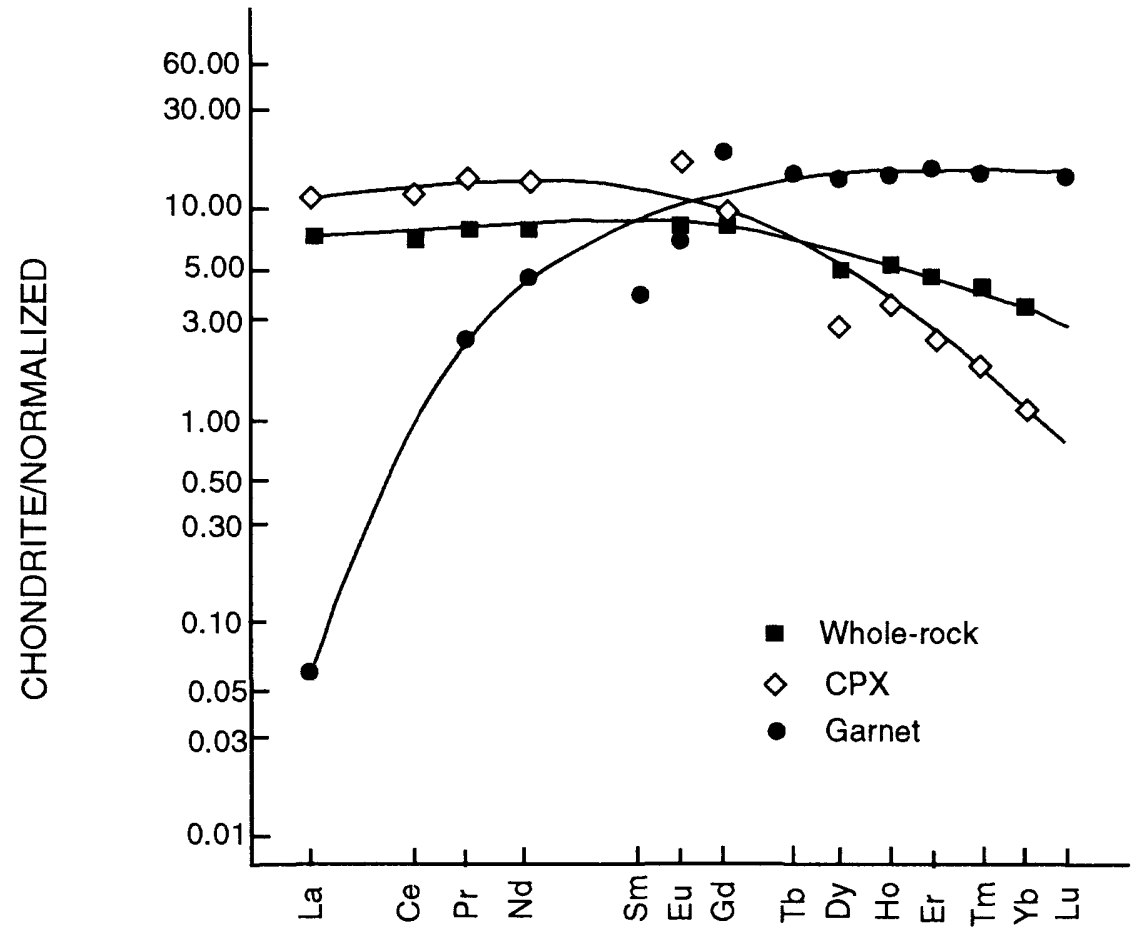

Fig. 1 Chondrite-normalized REE abundance patterns in whole-rock (square), clinopyroxene (diamond) and garnet (circle) from R7401 garnet pyroxenite, Salt Lake Crater, Hawaii (Reid and Frey, 1971). Solid lines drawn through the plots represent the smoothed abundance data used to calculate the REE partition coefficients for garnet and the proportion of mineral phases: cpx, gar and ol+. 


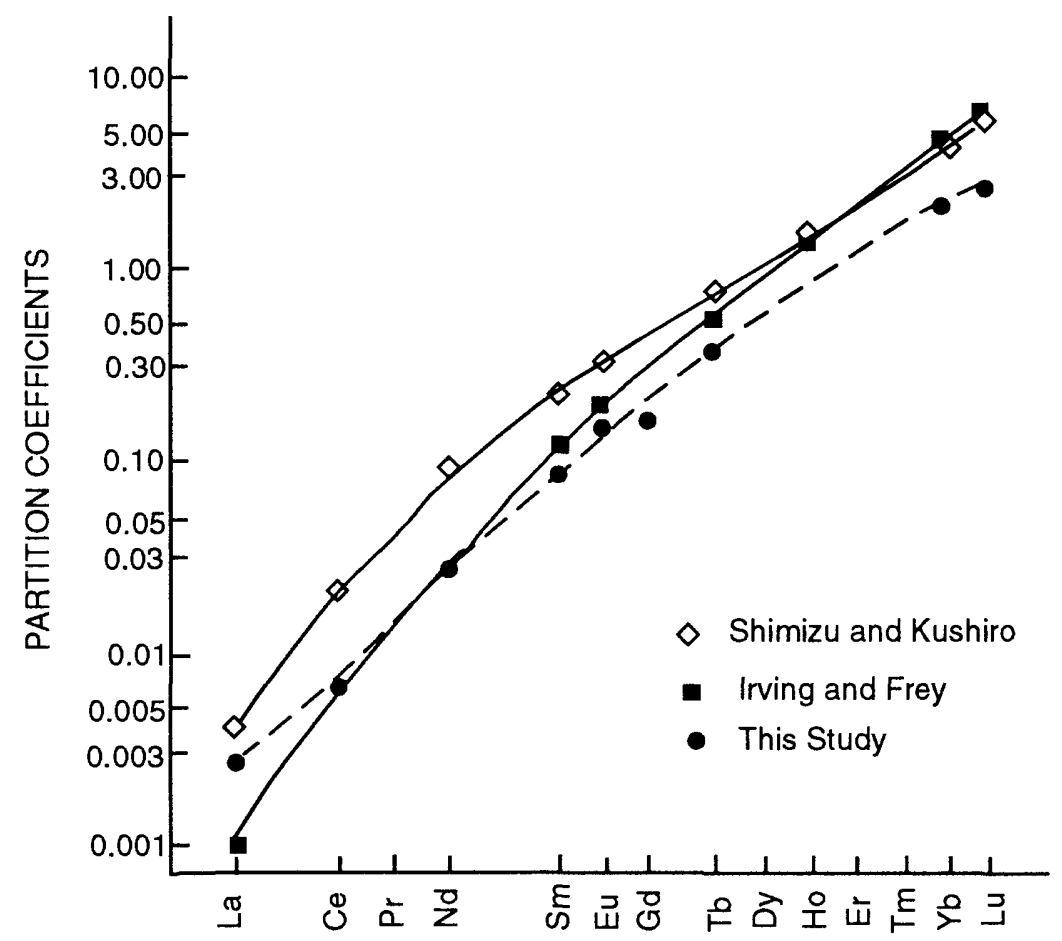

Fig. 2 Garnet/liquid partition coefficients. The diamonds and squares connected by solid lines are the experimentally determined values of Shimizu and Kushiro (1975) and Irving and Frey (1978), respectively, obtained from garnet/basalt pairs. The circles connected by a dashed line are the partition coefficients calculated in this study (see text). 


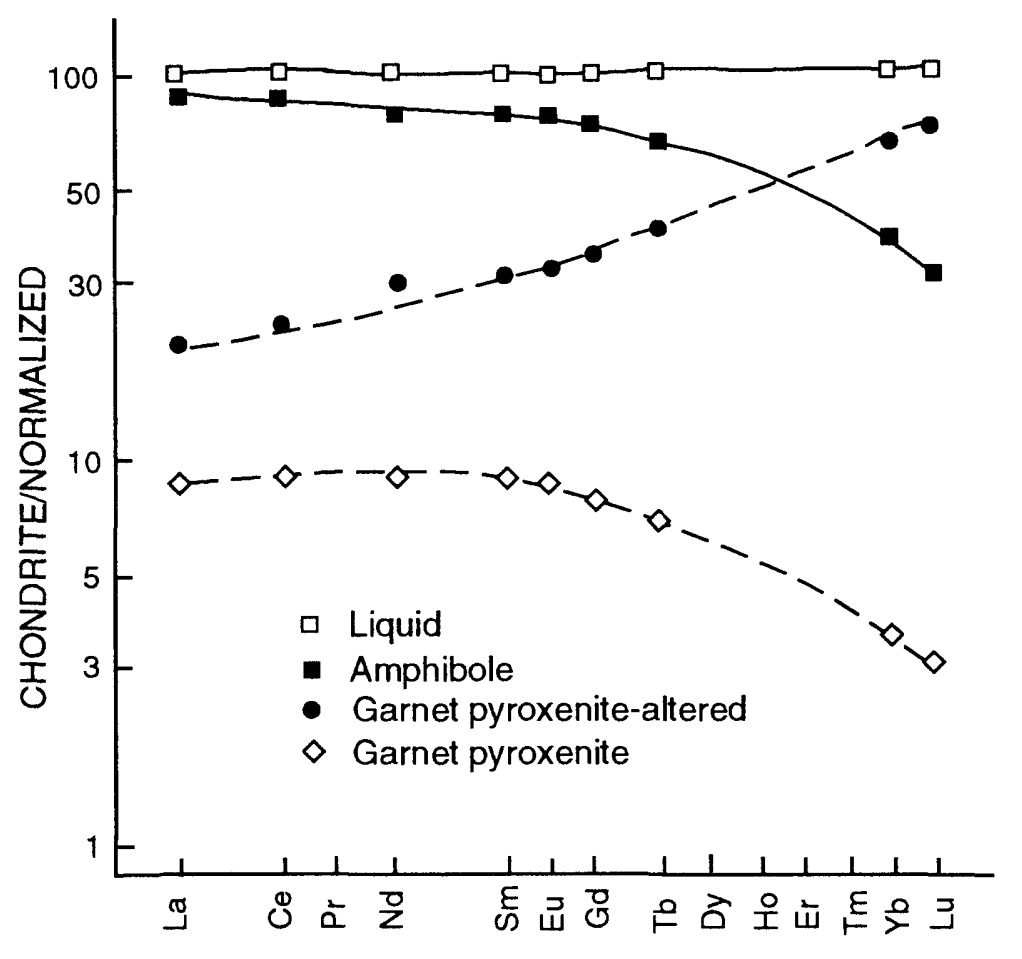

Fig. 3 Chondrite-normalized REE abundance patterns of a hypothetical liquid with a bulk amphibole composition and garnet pyroxenite prior to equilibration (open symbols). The REE abundances in the resultant crystallized amphibole and altered garnet pyroxenite are plotted as closed symbols and are calculated using the proposed mineral-mineral partitioning equation (Eqn. 4). Equilibrium conditions are assumed for REE partitioning. 


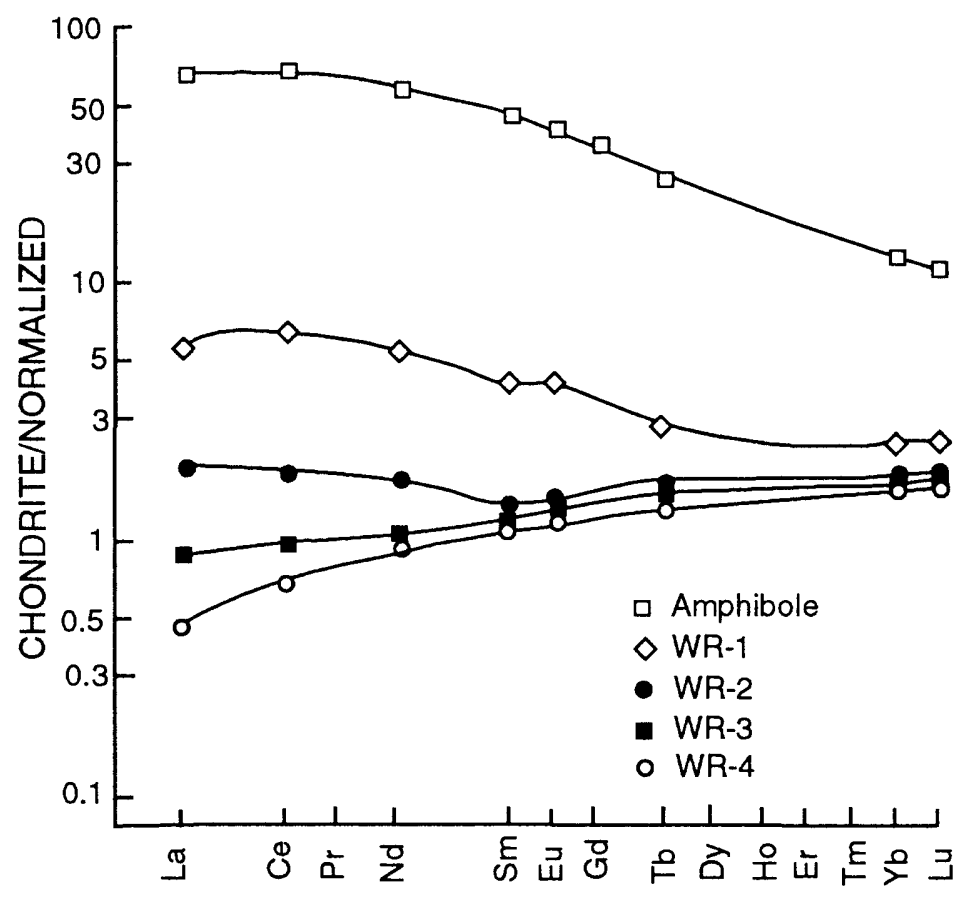

Fig. 4 Chondrite-normalized REE abundance patterns of four whole-rock subsamples (WR-1 through WR-4) from the $\mathrm{Ba}-2-1$ composite xenolith sample and of the amphibole-bearing vein. The amphibole REE concentrations represent the average of two compositions reported by Menzies, et al. (1985). Chondrite-normalization values used are in ppm: $\mathrm{La}=0.311, \mathrm{Ce}=0.813, \mathrm{Nd}=0.604, \mathrm{Sm}=0.196, \mathrm{Eu}=0.074$, $\mathrm{Gd}=0.26, \mathrm{Dy}=0.323, \mathrm{~Tb}=0.047, \mathrm{Er}=0.21, \mathrm{Yb}=0.21$, $\mathrm{Lu}=0.0323$. These values were obtained by multiplying 1.32 times the $C 1$ compiled data of Anders and Ebihara (1982). 


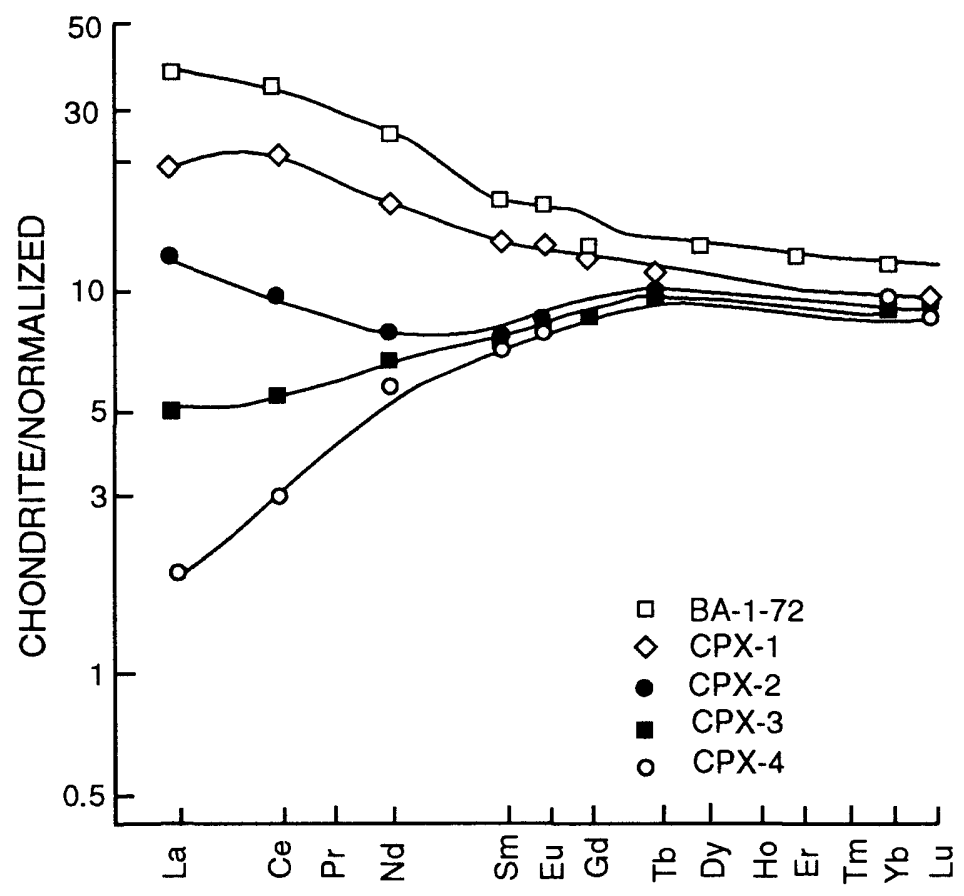

Fig. 5 Chondrite-normalized REE abundance patterns of clinopyroxene separates ( $\mathrm{CPX}-1$ through $\mathrm{CPX}-4$ ) from four subsamples of the Ba-2-1 composite xenolith and of a clinopyroxene separate from the Ba-1-72 xenolith (Menzies, et al., 1985). 


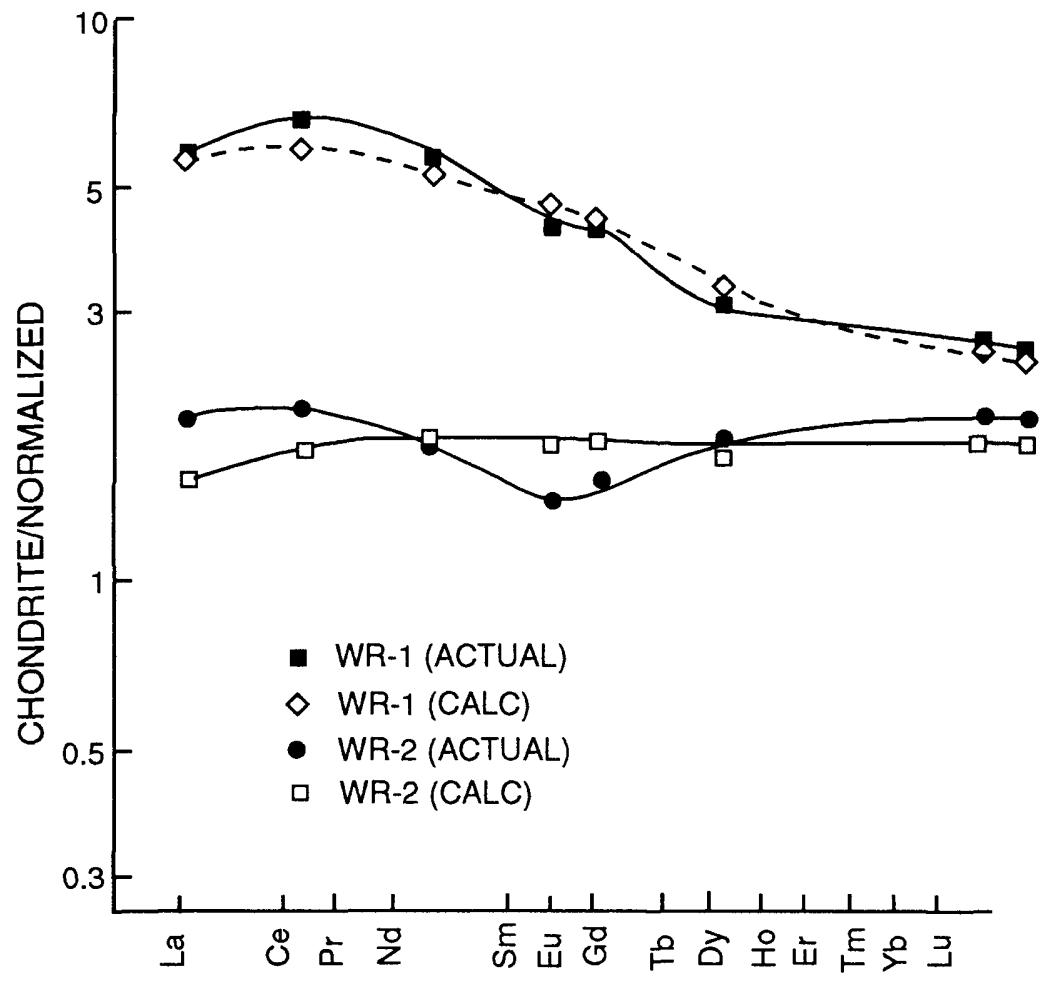

Fig. 6 Chondrite-normalized REE abundances in WR-1 and WR-2 subsamples (filled symbols) compared to the patterns that result from simple mixing of the amphibole vein material with the WR-4 subsample (open symbols). The best fit (diamond) to the actual WR-1 pattern (filled square) requires the addition of about $8 \%$ amphibole to the WR-4 subsample. The best fit (open square) to the actual WR-2 pattern (circle) requires that $2 \%$ amphibole be added to the WR-4 subsample. 
Fig. 7 Diagram contrasting simple mixing to diffusion-controlled mineral-mineral partitioning as a function of distance in the Ba-21 peridotite-hornblendite xenolith sample.

(A) Simple mixing. Liquid compositions similar to that of the amphibole vein material infiltrate or intrude the peridotite. The weight ratio of $\mathrm{x}_{\mathrm{AMP}} / \mathrm{x}_{\mathrm{WR}-4}=0.087$, for example, calculated from this model corresponds to the relative weights of infiltrated amphibole $\left(\mathrm{x}_{\mathrm{AMP}}=0.08\right)$ versus the unaltered $\mathrm{WR}-4$ subsample $\left(\mathrm{x}_{\mathrm{WR}-4}=0.92\right)$; see Fig. 6 .

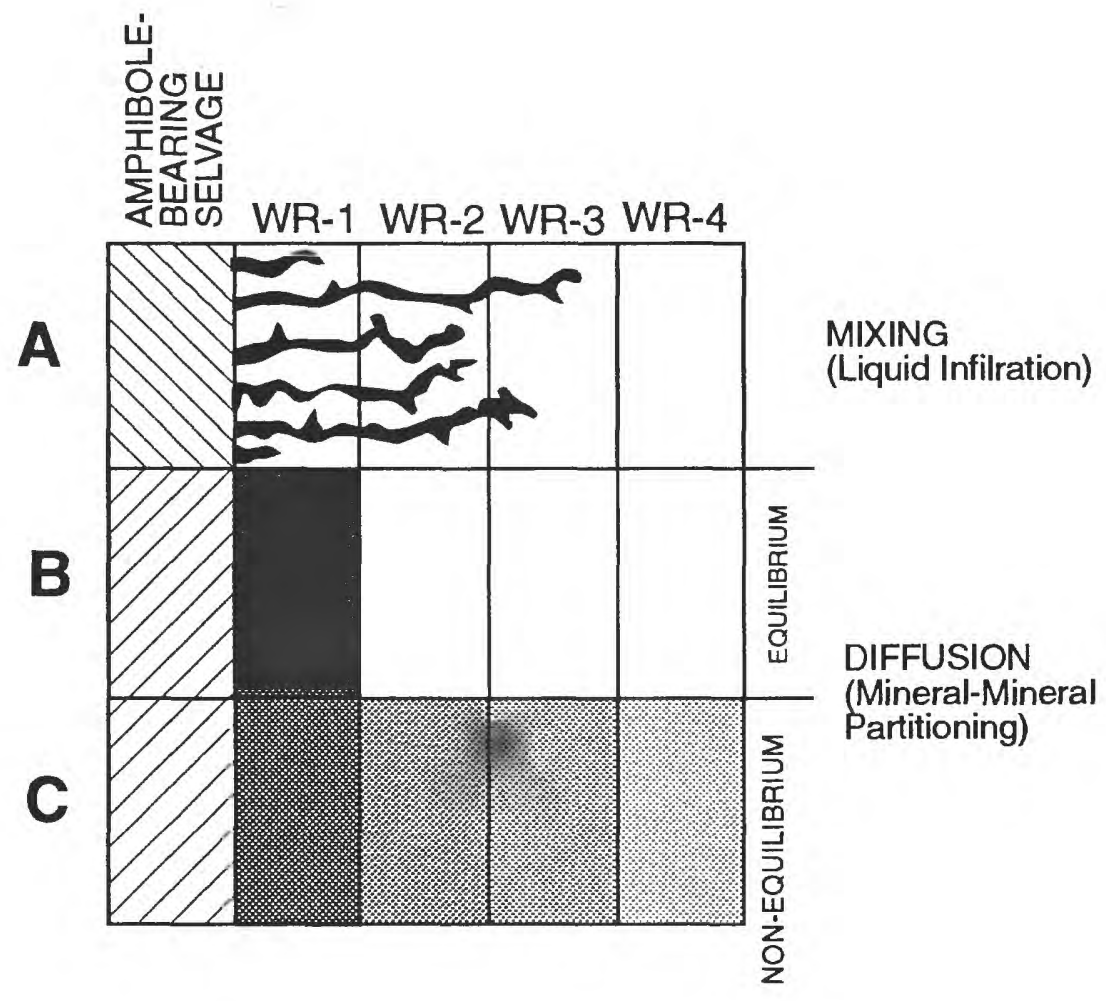

(B) Equilibrium mineral-mineral partitioning. This diagram depicts the mutual exchange of REE between the amphibole vein and the WR-1 subsample only, as dictated by an equilibrium relationship. The condition of REE equilibrium is indicated by the uniform shading of the WR-1 subsample. The weight ratios of $\mathrm{x}_{\mathrm{AMP}} / \mathrm{x}_{\mathrm{SUBSAMPLE}}$ calculated by this model (e.g. $x_{\mathrm{AMP}} / \mathrm{x}_{\mathrm{WR}-1}=1.0$ ) correspond to the relative weights of the amphibole-bearing selvage $\left(\mathrm{x}_{\mathrm{AMP}}=0.5\right)$ versus the affected peridotite subsample $\left(x_{\mathrm{WR}-1}=0.5\right)$.

(C) Non- or partial equilibrium partitioning. The REE from the amphibole vein are partitioned into the peridotite with no or limited exchange among the components as indicated by variable shading of the subsamples. Weight ratios of $\mathrm{x}_{\mathrm{AMP}} / \mathrm{x}_{\text {SUBSAMPLE }}$ calculated by this model correspond to the same ratio calculated from the equilibrium version. 


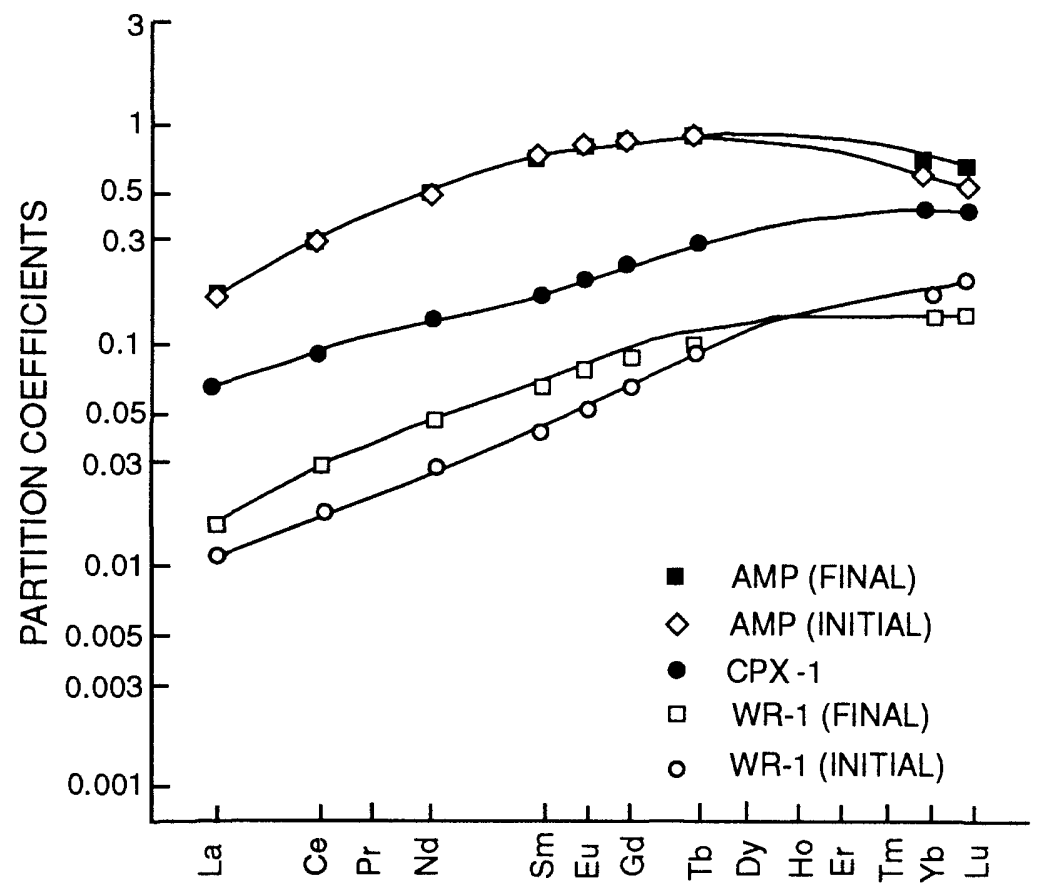

Fig. 8 Relative REE partition coefficients for amphibole, CPX-1 and WR-1 determined from modeling the amphibole:WR-1 system. The initial partition coefficients for amphibole and WR-1 are those obtained in the preliminary calculation using Eqn. 8 to determine the proportions of the phases involved in the REE partitioning process. The final partition coefficients are the further adjusted set of more internally consistent $D$ values that are constrained to best account for the observed REE abundances in $\mathrm{CPX}-1$. 


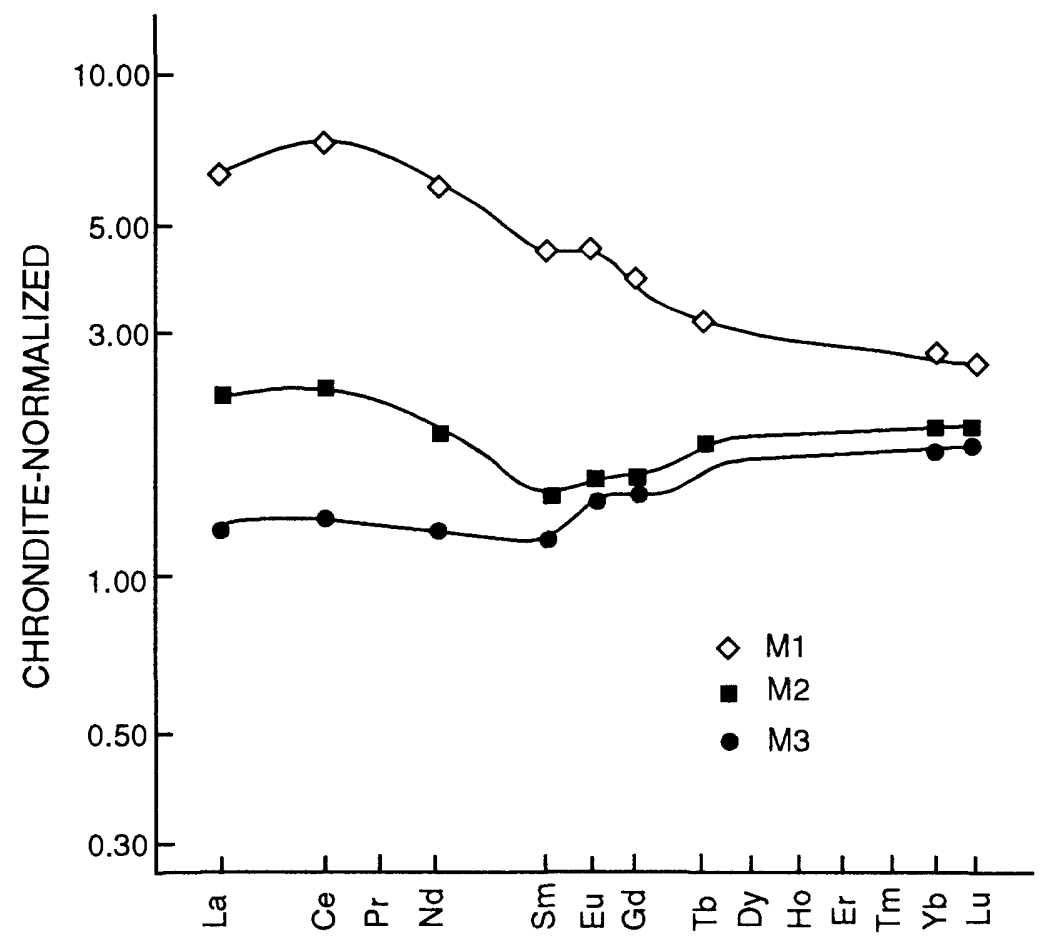

Fig. 9 Calculated chondrite-normalized REE abundance patterns of the metasomatic components introduced to each whole-rock subsample. The presence of these components is assumed in the non-equilibrium versions of the partitioning model. The REE patterns of the components are constrained by the REE abundances of the cpx separates in each subsample. The M1 concentrations are about $90 \%$ of the REE concentrations of the WR-1 subsample; the M2 concentrations are about $80 \%$ of the REE concentrations of the WR-2 subsample; and M3 are 50\% of the REE concentrations of the WR-3 subsample. 


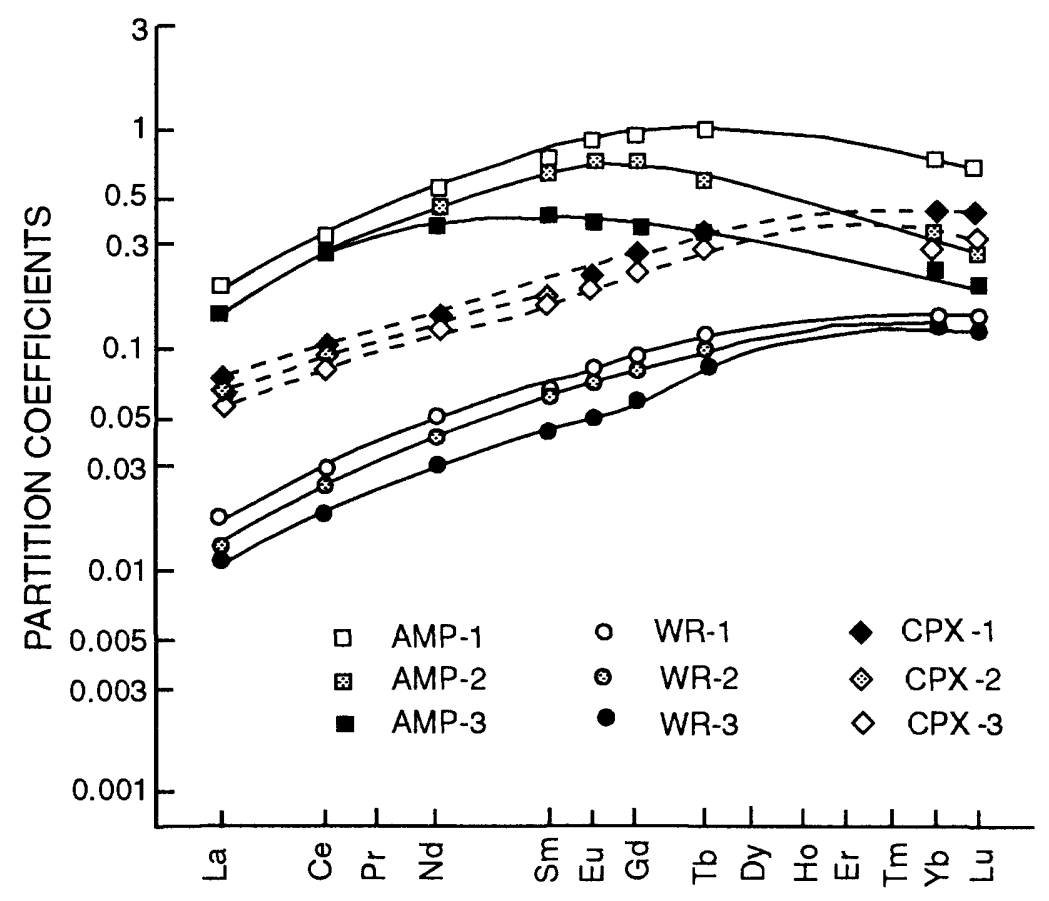

Fig. 10 Final, apparent REE partition coefficients for the amphibole in each subsystem and the operative REE partition coefficients for the clinopyroxenes and whole-rock subsamples. These final $D$ values are based on the non-equilibrium version, but are adjusted in order to be more consistent with the modal compositions of the whole rocks. The adjustments were primarily made to the AMP-1, WR-1 and $C P X-1$ values and reflect the differences inferred between the modal compositions of the WR-1 and the WR-2 subsamples. 


\section{REFERENCES}

Anders E. and Ebihara M. (1982) Solar system abundances of the elements. Geochim. Cosmochim. Acta 46, 2363-2380.

Bodinier J.L., Guirand M., Fabries J., Dostal J., and Dupuy C. (1987) Petrogenesis of layered pyroxenites from the Lherz, Freychinede and Prades ultramafic bodies (Ariege, French Pyrenees). Geochim. Cosmochim. Acta 51, 279-290.

Bodinier J.L., Vasseur A., Vernieres J., Dupuy C., and Fabries J. (1990) Mechanisms of mantle metasomatism: geochemical evidence from the Lherz orogenic peridotite. J. Petrol. 31, 597-628.

Frey Fred A. (1970) Rare earth element abundances in alpine ultramafic rocks. Phys. Earth Planet. Interiors 3, 323-330.

Gast P.W. (1968) Trace element fractionation and the origin of tholeite and alkaline magma types. Geochim. Cosmochim. Acta 32, 1057-1086.

Grauch R.I. (1989) Rare earth elements in metamorphic rocks. In Geochemistry and Mineralogy of Rare Earth Elements (eds. B.R. Lipin and G.A. McKay), Reviews in Mineralogy Vol. 21, Chap. 6, pp. 147-168. Mineralogical Society of America.

Hanson G.N. (1989) An approach to trace element modeling using a simple igneous system as an example. In Geochemistry and Mineralogy of Rare Earth Elements (eds. B.R. Lipin and G.A. McKay), Reviews in Mineralogy, Vol. 21, Chap. 4, pp. 79-97. Mineralogical Society of America.

Harte B., Winterburn, P.A. and Gurney, J.J. (1987) Metasomatic and enrichment phenomena in garner peridotite facies mantle xenoliths from the Matsoku kimberlite pipe, Lesotho. In Mantle Metasomatism (eds. Menzies, M.A. et al.), pp. 145220, Academic Press.

Irving A.J. (1978) A review of experimental studies of crystal/liquid trace element partitioning. Geochim. Cosmochim. Acta 42, 743-770.

Irving A.J. and Frey F.A. (1978) Distribution of trace elements between garnet megacrysts and host volcanic liquids of kimberlite to rhyolitic composition. Geochim. Cosmochim. Acta $42,771-787$.

Irving A.J. and Frey F.A. (1984) Trace element abundances in megacrysts and their host basalts: Constraints on partition coefficients and megacryst genesis. Geochim. Cosmochim. Acta $48,1201-1221$.

Kurat G., Palme H., Spettel B., Baddenhausen H., Hofmeister H., Palme C., and Wanke H. (1980) Geochemistry of ultramafic xenoliths from Kapfenstein, Austria: Evidence for a variety of upper mantle processes. Geochim. Cosmochim. Acta 44, 61-84.

Liang Y. and Elthon D. (1990) Geochemistry and petrology of spinel therzolite xenoliths from Xalapasco de La Joya, San Luis Potosi, Mexico: Partial melting and mantle metasomatism. J. Geophys. Res. 95, 15859-15877. 
McKay G.A. (1989) Partitioning of rare earth elements between major silicate minerals and basaltic melts. In Geochemistry and Mineralogy of Rare Earth Elements (eds. B.R. Lipin and G.A. McKay), Reviews in Mineralogy Vol. 21, Chap. 3, pp. 45-77. Mineralogical Society of America.

Menzies M.A., Kempton P.D., and Dungan M.A. (1985) Interactions of continental lithosphere and asthenosphere melts below the Geronimo volcanic field, Arizona, U.S.A. J. Petrol. 26, 663-693.

Navon 0. and Stolper E. (1987) Geochemical consequences of melt percolation: The upper mantle as a chromatographic column. J. Geol. 95, 285-307.

Neumann H., Mead J., and Vitaliano C.J. (1954) Trace element variations during fractional crystallization from the distribution law. Geochim. Cosmochim. Acta 6, 90-99.

Nielson J.E. and Noller J.S. (1987) Processes of mantle metasomatism: Constraints from observations of composite peridotite xenoliths. Geol. Soc. Amer. Special Paper 215, pp. 61-76.

Nielson J.E., Budahn J.R., Unruh D.M., and Wilshire H.G. (1993) Actualistic models of mantle metasomatism documented in a composite xenolith from Dish Hill, California. Geochim. Cosmochim. Acta 57, 105-121.

ottonello G. (1980) Rare earth abundances and distribution in some spinel peridotite xenoliths from Assab (Ethiopia). Geochim. Cosmochim. Acta 44, 1885-1901.

Philpotts J.A., Schnetzler C.C., and Thomas H.H. (1972) Petrogenetic implications of some new geochemical data on eclogite and ultrabasic inclusions. Geochim. Cosmochim. Acta 36, 1131-1166.

Prinzhofer A. and Allegre C.J. (1985) Residual peridotite and the mechanism of partial melting. Earth. Planet. Sci. Lett. $74,251-265$.

Reid J.B. and Frey F.A. (1971) Rare earth distributions in lherzolite and garnet pyroxenite xenoliths and the constitution of the upper mantle. J. Geophys. Res. 76, 1184-1196.

Shaw D.M. (1970) Trace element fractionation during anatexis. Geochim. Cosmochim. Acta 34, 237-242.

Shilling J.-G. (1966) Rare earth fractionation in Hawaiian rocks. Unpub. Ph.D thesis, Mass. Inst. Tech., Cambridge MA.

Shimizu N. and Kushiro I. (1975) The partitioning of rare earth elements between garnet and liquid at high pressures: preliminary experiments. Geophys. Res. Lett. 2, 413-416.

Song Y. and Frey F.A. (1989) Geochemistry of peridotite xenoliths in basalt from Hannuoba, Eastern China: Implications for subcontinental mantle heterogeneity. Geochim. Cosmochim. Acta 53, 97-113.

Stosch H.G. (1982) Rare earth element partitioning between minerals from anhydrous spinel peridotite xenoliths. Geochim. Cosmochim. Acta 46, 793-811. 
Wilshire H.G. (1984) Mantle metasomatism: The REE story. Geology 12 , 395-398.

Wilshire H.G., Pike J.E.N., Meyer C.E., and Schwarzman E.L. (1980) Amphibole-rich veins in therzolite xenolith, Dish Hill and Deadman Lake, California. Amer. J. Sci. 280A, The Jackson Volume, 576-593.

Wilshire H.G., Meyer C.E., Nakata J.K., Calk L.C., Shervais J.W., Nielson J.E. and Schwarzman E.L. (1988) Mafic and Ultramafic Xenoliths from Volcanic Rocks of the Western United States. U.S. Geological Survey Professional Paper 1443, U.S. Government Printing Office, Washington D.C. 179 p. 